\title{
Segregation of the human medial prefrontal cortex in social cognition
}

\section{Danilo Bzdok ${ }^{1,2}$, Robert Langner $^{1,2}$, Leonhard Schilbach ${ }^{3,4}$, Denis A. Engemann ${ }^{4,5}$, Angela R. Laird ${ }^{6}$, Peter T. Fox ${ }^{7,8}$ and Simon B. Eickhoff ${ }^{1,2 *}$}

1 Institute of Neuroscience and Medicine (INM-1), Research Center Jülich, Jülich, Germany

2 Institute of Clinical Neuroscience and Medical Psychology, Heinrich Heine University, Düsseldorf, Germany

${ }^{3}$ Max-Planck-Institute for Neurological Research, Cologne, Germany

${ }^{4}$ Department of Psychiatry, University of Cologne, Cologne, Germany

${ }^{5}$ Institute of Neuroscience and Medicine (INM-3), Research Center Jülich, Jülich, Germany

${ }^{6}$ Department of Physics, Florida International University, Miami, FL, USA

7 Research Imaging Institute, University of Texas Health Science Center, San Antonio, TX, USA

${ }^{8}$ South Texas Veterans Administration Medical Center, San Antonio, Texas

\section{Edited by:}

Leonie Koban, University of Colorado Boulder, USA

\section{Reviewed by:}

Derek E. Nee, Indiana University, USA

Mathieu Roy, University of Colorado Boulder, USA

\section{${ }^{*}$ Correspondence:}

Simon B. Eickhoff, Institut für Neurowissenschaften und Medizin (INM-1), Forschungszentrum Jülich $\mathrm{GmbH}$, Building 23.02,

Universitätsstr 1, D-52425 Jülich

Germany

e-mail: s.eickhoff@fz-juelich.de

While the human medial prefrontal cortex (MPFC) is widely believed to be a key node of neural networks relevant for socio-emotional processing, its functional subspecialization is still poorly understood. We thus revisited the often assumed differentiation of the $\mathrm{mPFC}$ in social cognition along its ventral-dorsal axis. Our neuroinformatic analysis was based on a neuroimaging meta-analysis of perspective-taking that yielded two separate clusters in the ventral and dorsal mPFC, respectively. We determined each seed region's brain-wide interaction pattern by two complementary measures of functional connectivity: co-activation across a wide range of neuroimaging studies archived in the BrainMap database and correlated signal fluctuations during unconstrained ("resting") cognition. Furthermore, we characterized the functions associated with these two regions using the BrainMap database. Across methods, the ventral mPFC was more strongly connected with the nucleus accumbens, hippocampus, posterior cingulate cortex, and retrosplenial cortex, while the dorsal mPFC was more strongly connected with the inferior frontal gyrus, temporo-parietal junction, and middle temporal gyrus. Further, the ventral mPFC was selectively associated with reward related tasks, while the dorsal mPFC was selectively associated with perspective-taking and episodic memory retrieval. The ventral mPFC is therefore predominantly involved in bottom-up-driven, approach/avoidance-modulating, and evaluation-related processing, whereas the dorsal mPFC is predominantly involved in top-down-driven, probabilistic-scene-informed, and metacognition-related processing in social cognition.

Keywords: social cognition, medial prefrontal cortex, meta-analytic connectivity modeling, resting state connectivity, functional decoding, data-mining

\section{INTRODUCTION}

Functional specialization in the human prefrontal cortex has been investigated since the middle of the nineteenth century primarily by lesion reports (Harlow, 1848, 1868; Broca, 1865). However, hard evidence derivable from functional double dissociations by prefrontal brain lesions is rare in humans (cf. Gaffan, 2002; Wilson et al., 2010). Nevertheless, the parts of the prefrontal cortex are known to be involved in many high-level cognitive functions, including executive control, action selection, multitasking, social cognition, or general intelligence. These disparate roles have been parsimoniously explained by different concepts, including the conjoint consideration of internal subtasks, branching and reallocation of attention, or balancing between selfgenerated and environmental information. Yet, there may be no common denominator for all functional involvements of the PFC (Wood and Grafman, 2003; Ramnani and Owen, 2004; Amodio and Frith, 2006; Burgess et al., 2006; Koechlin and Hyafil, 2007; Forbes and Grafman, 2010; O’Reilly, 2010).
In contrast, activity changes in medial aspects of the prefrontal cortex (mPFC) were frequently related to social cognition, defined as information processing related to human individuals as opposed to the physical world. Examples of such functional involvements include processing affective information (Phan et al., 2002), forming social judgments (Freeman et al., 2010; Bzdok et al., 2012b), attributing beliefs (den Ouden et al., 2005), retrieving social semantic knowledge (Contreras et al., 2012), and encountering unstable social hierarchies (Zink et al., 2008). In fact, Mitchell (2009) noted that the core domains of social psychology converge exclusively in the MPFC, rendering this scientific field naturally coherent rather than an arbitrary outcome of historical evolution. In social neuroscience, most propositions for functional specialization of the mPFC relied on the distinction between a ventral and a dorsal functional compartment. More specifically, ventral versus dorsal mPFC regions (vmPFC/dmPFC) have been variously proposed to be functionally dissociable according to emotional versus cognitive, 
automatic versus controlled, implicit versus explicit, outcomeoriented versus goal-oriented, or self-relevant versus otherrelevant social cognition (Amodio and Frith, 2006; Mitchell et al., 2006; Shamay-Tsoory et al., 2006; Lieberman, 2007; Olsson and Ochsner, 2008; Van Overwalle, 2009; Forbes and Grafman, 2010). The diversity of proposed functional dissociations between the vmPFC and dmPFC illustrates the current lack of consensus.

In the current study, we therefore quantitatively examined the functional organization of the MPFC along its ventrodorsal axis. First, the analysis was based on two seed regions in the vmPFC and $\mathrm{dmPFC}$, respectively. These regions corresponded to locations showing significant convergence of perspective-taking tasks in a recent coordinate-based meta-analysis (Bzdok et al., 2012c). As perspective-taking is probably a uniquely human capacity (Premack and Woodruff, 1978; Tomasello et al., 2003), these two clusters of underlying convergent activity are an excellent proxy for the different functional compartments of the mPFC in human social cognition in general. Second, we delineated brain-wide connectivity of each seed according to two complementary measures of functional connectivity, task-dependent meta-analytic connectivity modeling (MACM, Eickhoff et al., 2011) and taskindependent resting state correlations (RS, Biswal et al., 1995). MACM analysis is based on co-activation patterns across a large number of databased neuroimaging experiments (i.e., brain activity under task constraints). RS analysis, in turn, is based on correlations of slow $(<0.1 \mathrm{~Hz})$ fluctuations of fMRI signals during rest (i.e., unconstrained brain activity in the absence of an externally purported task). Third, we determined a functional profile for each seed using BrainMap meta-data (Laird et al., 2011) by complementary forward and reverse functional decoding. This approach allowed for a cross-validated connectional and functional segregation of the ventral and dorsal mPFC segregation as involved in social cognition.

\section{METHODS}

\section{DEFINITION OF THE SEED REGIONS}

We conducted connectivity analyses and functional profiling of two seed regions in the $\mathrm{MPFC}$ that were derived from a recent coordinate-based meta-analysis (Bzdok et al., 2012c) using the activation-likelihood estimation (ALE) algorithm (Eickhoff et al., 2009, 2012; Eickhoff and Bzdok, 2012). This meta-analysis quantitatively summarized all neuroimaging experiments related to perspective-taking published until 2010, in all, 68 experiments reporting 724 activation foci (Bzdok et al., 2012c). It included neuroimaging experiments [fMRI and positron emission tomography $(\mathrm{PET})]$ in which participants were required to adopt an intentional stance towards others, that is, predict their thoughts, intentions, and future actions. It excluded neuroimaging experiments using non-whole-brain analyses, pharmacological manipulations, or psychiatrically/neurologically diagnosed individuals. More specifically, the two chosen seed regions represent regions of converging brain activity revealed by the (cluster-level corrected) quantitative meta-analysis of neuroimaging results from various paradigms that prompt perspective-taking. Please note that the meta-analyses on empathy and morality, also reported in that meta-analytic study, did not contribute to our seeds. The previously published meta-analysis on perspective-taking thus yielded two continuous, non-overlapping clusters of convergent brain activity that served as neuroanatomical constraints for the differential localization of higher social processes in the mPFC. Put differently, those seeds reflect, first, two topographically constrained brains areas closely related to social processes and, second, the widely assumed functional segregation in this area in the neuroimaging literature on social cognition (e.g., Mitchell et al., 2006; Shamay-Tsoory et al., 2006; Van Overwalle, 2009). Each cluster's whole-brain connectivity pattern was subsequently delineated by task-dependent meta-analytic connectivity modeling and task-independent resting-state analyses. As the employed meta-analytic seeds naturally have asymmetrical shapes we repeated all analyses after fusion of the original seeds with the sagitally mirrored seeds, which yielded virtually identical results.

\section{TASK-DEPENDENT FUNCTIONAL CONNECTIVITY: MACM}

The delineation of whole-brain co-activation maps for each seed was performed based on the BrainMap database (www.brainmap. org; Fox and Lancaster, 2002; Laird et al., 2011). We constrained our analysis to "normal" fMRI and PET experiments (i.e., no pharmacological interventions, no group comparisons) in healthy participants, which report whole-brain results as coordinates in a standard stereotaxic space. These inclusion criteria yielded $\sim 6500$ eligible experiments at the time of analysis. Note that we considered all eligible BrainMap experiments because any pre-selection based on taxonomic categories would have constituted a strong a priori hypothesis about how different tasks etc. involve different brain networks. Yet, it remains elusive how well psychological constructs, such as emotion and cognition, map on regional brain responses (Mesulam, 1998; Poldrack, 2006; Laird et al., 2009a). To reliably determine the co-activation patterns of a given seed, we identified the set of experiments in BrainMap that reported at least one activation focus within that seed. The brain-wide co-activation pattern for each seed was then computed by ALE meta-analysis over (all foci reported in) the experiments that were associated with that particular seed (Turkeltaub et al., 2002; Eickhoff et al., 2009; Laird et al., 2009a). The key idea behind ALE is to treat the foci reported in the associated experiments not as single points, but as centers for $3 \mathrm{D}$ Gaussian probability distributions that reflect the spatial uncertainty associated with neuroimaging results. Using the latest ALE implementation (Eickhoff et al., 2009, 2012; Turkeltaub et al., 2012), the spatial extent of those Gaussian probability distributions was based on empirical estimates of between-subject and between-template variance of neuroimaging foci (Eickhoff et al., 2009). For each experiment, the probability distributions of all reported foci were then combined into a modeled activation (MA) map by the recently introduced "non-additive" approach that prevents local summation effects (Turkeltaub et al., 2012). The voxel-wise union across the MA maps of all experiments associated with a particular seed voxel then yielded an ALE score for each voxel of the brain that describes the coactivation probability of that particular location with the current seed voxel.

To establish which regions were significantly co-activated with a particular seed, ALE scores for the MACM analysis of this 
seed were compared to a null-distribution that reflects a random spatial association between experiments, but regards the within-experiment distribution of foci as fixed (Eickhoff et al., 2009). This random-effects inference assesses above-chance convergence between experiments. The observed ALE scores from the actual meta-analysis of experiments activating within a particular seed were then tested against the ALE scores obtained under this null-distribution yielding a p-value based on the proportion of equal or higher random values (Eickhoff et al., 2012). The resulting $\mathrm{p}$-values were then thresholded at $p<0.05$ with cluster-level family-wise error correction for multiple comparisons (clusterforming threshold at voxel-level: $p<0.001$ ).

Differences in co-activation patterns between the seeds were assessed by first performing MACM separately on the experiments associated with either seed and computing the voxel-wise difference between the ensuing ALE maps (Eickhoff et al., 2011). All experiments contributing to either analysis were then pooled and randomly divided into two groups of the same size as the two original sets of experiments. That is, if 100 experiments in BrainMap featured activation in seed A and 75 featured activation in seed B, the resulting pool of (175) experiments would be randomly divided into a group of 100 and a group of 75 experiments. ALE-scores for these two randomly assembled groups were calculated and the difference between these ALE-scores was recorded for each voxel in the brain. Repeating this process 10,000 times yielded an empirical null-distribution for the differences in ALE-scores between the MACM analyses of the two seeds. The observed difference in ALE scores was then tested against this null-distribution yielding a p-value for the difference at each voxel based on the proportion of equal or higher random differences. The resulting non-parametric $\mathrm{p}$-values were thresholded at $p>$ 0.95 and inclusively masked by the respective main effects, i.e., the already thresholded effects from the MACM analysis of the particular seed, to focus inference on regions reliably co-activating with that seed.

\section{TASK-INDEPENDENT FUNCTIONAL CONNECTIVITY: RS CORRELATIONS}

Next, seed-wise whole-brain connectivity was assessed using resting-state correlations as an independent modality of functional connectivity. This analysis was based on RS fMRI data from 139 healthy volunteers ( 56 female, mean age 42.3 years) without any record of neurological or psychiatric disorders. This dataset was obtained through the 1000 Functional Connectomes Project as part of the NKI/Rockland sample (http://fcon_1000.projects. nitrc.org/indi/pro/nki.html). Participants were instructed to keep their eyes closed and just let their mind wander without thinking of anything in particular but not to fall asleep. For each participant, 260 RS echo-planar imaging (EPI) volumes were acquired on a Siemens TimTrio 3T scanner using blood-oxygen-leveldependent (BOLD) contrast [gradient-echo EPI pulse sequence, $\mathrm{TR}=2.5 \mathrm{~s}, \mathrm{TE}=30 \mathrm{~ms}$, flip angle $=80^{\circ}$, in-plane resolution $=$ $3.0 \times 3.0 \mathrm{~mm}^{2}, 38$ axial slices (3.0 mm thickness) covering the entire brain]. The first four scans served as dummy images allowing for magnetic field saturation and were discarded prior to further processing using SPM8 (www.fil.ion.ucl.ac.uk/spm). The EPI images were first corrected for head movement by affine registration using a two-pass procedure. The mean EPI image for each participant was then spatially normalized to the MNI single-subject template (Holmes et al., 1998) using the 'unified segmentation' approach (Ashburner and Friston, 2005) and the ensuing deformation was applied to the individual EPI volumes. Finally, images were smoothed by a $5-\mathrm{mm}$ FWHM Gaussian kernel to improve signal-to-noise ratio and compensate for residual anatomical variations.

The time-series data of each individual seed voxel were processed as follows (zu Eulenburg et al., 2012; Satterthwaite et al., 2013): In order to reduce spurious correlations, variance that could be explained by the following nuisance variables was removed: (1) The six motion parameters derived from the image realignment, (2) the first derivative of the realignment parameters, and (3) mean gray-matter, white-matter, and cerebrospinal fluid signal per time-point as obtained by averaging across voxels attributed to the respective tissue class in the SPM eight segmentation. All of these nuisance variables entered the model as firstand second-order terms (Jakobs et al., 2012; Reetz et al., 2012; Satterthwaite et al., 2013). Data were then band-pass filtered preserving frequencies between 0.01 and $0.08 \mathrm{~Hz}$ since meaningful resting-state correlations will predominantly be found in these frequencies given that the BOLD response acts as a low-pass filter (Biswal et al., 1995; Fox and Raichle, 2007).

According to this procedure, time courses were extracted for all voxels of a given seed of the individual participant and the time course of the entire seed was then expressed as the first eigenvariate of its voxels' time courses. Pearson correlation coefficients between the time series of the seeds and all other gray-matter voxels in the brain were computed to quantify RS connectivity. These voxel-wise correlation coefficients were then transformed into Fisher's Z-scores and tested for consistent deviation from zero across participants in a random-effects analysis. In particular, the Fisher's Z transformed whole-brain connectivity maps of all seeds were included in an ANOVA accounting for non-sphericity in the data originating from the fact that the different seeds represented correlated measures within each subject with unequal variance between seeds and subjects. Appropriate linear contrasts were then applied to test for regions significantly connected to the seed in the ventral and dorsal mPFC, respectively. The results of this random-effects difference analysis were cluster-level thresholded at $p<0.05$ (cluster-forming threshold at voxel-level: $p<0.001$ ), analogous to the MACM-based difference analysis.

\section{CONJUNCTION AND DIFFERENCE ANALYSES ACROSS BOTH CONNECTIVITY MODALITIES}

To identify brain areas showing convergent task-dependent and task-independent functional connectivity with an individual seed, we performed a conjunction analysis across the MACM- and RS-derived (cluster-level corrected) connectivity maps using the strict minimum statistics (Nichols et al., 2005; Jakobs et al., 2012). Thus, surviving voxels were functionally associated with a given seed in both task-constrained ("focused") and taskunconstrained ("resting") brain states.

The main focus was, however, on connectivity differences between the vmPFC and dmPFC seeds. To this aim, we identified regions with significantly stronger coupling with either seed across task-dependent and task-independent functional 
connectivity. That is, we computed the conjunction (across both connectivity modalities) of the contrasts (between seeds) to determine regions that were more strongly connected to the ventral or dorsal seed across two disparate brain states (Cieslik et al., 2012; Reetz et al., 2012; Rottschy et al., 2012).

\section{FUNCTIONAL PROFILING OF THE SEEDS}

The functional characterization of the two MPFC seeds was based on the BrainMap meta-data that describe each neuroimaging experiment included in the database. Behavioral domains code the mental processes isolated by the statistical contrasts (Fox et al., 2005) and comprise the main categories cognition, action, perception, emotion, and interoception, as well as their related subcategories. Paradigm classes categorize the specific task employed (Turner and Laird, 2012; for the complete BrainMap taxonomy, see http://brainmap.org/scribe/).

Forward inference on the functional characterization then tests the probability of observing activity in a brain region given knowledge of the psychological process, whereas reverse inference tests the probability of a psychological process being present given knowledge of activation in a particular brain region (Poldrack, 2006; Yarkoni et al., 2011). In the forward inference approach, a cluster's functional profile was determined by identifying taxonomic labels for which the probability of finding activation in the respective cluster was significantly higher than the overall chance (across the entire database) of finding activation in that particular cluster. Significance was established using a binomial test ( $p<0.001$; Eickhoff et al., 2011). In the reverse inference approach, a cluster's functional profile was determined by identifying the most likely behavioral domains and paradigm classes given activation in a particular cluster. Significance was then assessed by means of a chi-square test $(p<0.001)$. Base rates for activations in the respective clusters as well as base rates for tasks were taken into account using the Bayesian formulation for deriving $\mathrm{P}$ (Task|Activation) based on $\mathrm{P}$ (Activation|Task) as well as $\mathrm{P}$ (Task) and $\mathrm{P}$ (Activation). In sum, forward inference assesses the probability of activation given a psychological term, while reverse inference assesses the probability of a psychological term given activation (Cieslik et al., 2012; Reetz et al., 2012; Rottschy et al., 2012; Kellermann et al., 2013).

The contrast analyses between the two seeds' functional profiles, in turn, were constrained to those experiments in BrainMap activating either seed. That is, the task associations of experiments in this composite pool were quantified in comparison between the respective seeds and thresholded at $p<$ 0.05 (false-discovery-rate corrected for multiple comparisons). Forward inference here compared the activation probabilities between the two seeds given a particular psychological term, while reverse inference compared the probabilities of a particular psychological term being present given activation in one or the other seed. Please note that the contrast analysis results were masked with the respective individual functional decoding results of either seed. Put differently, a psychological term can only be significantly more associated with a seeds, if it was also determined significant in the main effect of functional decoding of that seed. Finally, conjunction analyses across the two seeds' functional profiles tested for significant associations of each particular psychological term with both seeds.

Notably, this approach aims at relating defined psychological tasks to the examined brain regions instead of claiming "a unique role" of a brain region for any psychological task (Mesulam, 1998; Poldrack, 2006; Yarkoni et al., 2011). Put differently, an association of task $\mathrm{X}$ to brain region $\mathrm{Y}$ obtained in these analyses does not necessarily imply that neural activity in region $\mathrm{Y}$ is limited to task X.

\section{RESULTS \\ FUNCTIONAL CONNECTIVITY: INDIVIDUAL ANALYSES OF SEEDS}

We first determined each seed's (Figure 1) functional connectivity separately by means of both task-dependent MACM and task-independent RS analyses (Figure 2 and Tables 1, 2). MACM analysis of the vmPFC seed yielded the bilateral vmPFC and dmPFC extending into the anterior cingulate cortex (ACC), amygdala/hippocampus (AM/HC), posterior cingulate cortex/retrosplenial cortex (PCC/RSC), as well as the left nucleus accumbens (NAc), temporo-parietal junction (TPJ), superior frontal gyrus, and posterior operculum (pOP). RS analysis of the vmPFC seed yielded the bilateral vmPFC and dmPFC extending into the ACC, AM, HC, NAc, posterior mid-cingulate cortex (pMCC), RSC/PCC, precuneus (Prec), TPJ, middle temporal gyrus (MTG), temporal pole (TP), precentral gyrus (PreG), pOP, and cerebellum (Cer, not depicted) as well as the right postcentral gyrus (PoG). MACM analysis of the dmPFC seed, in turn,

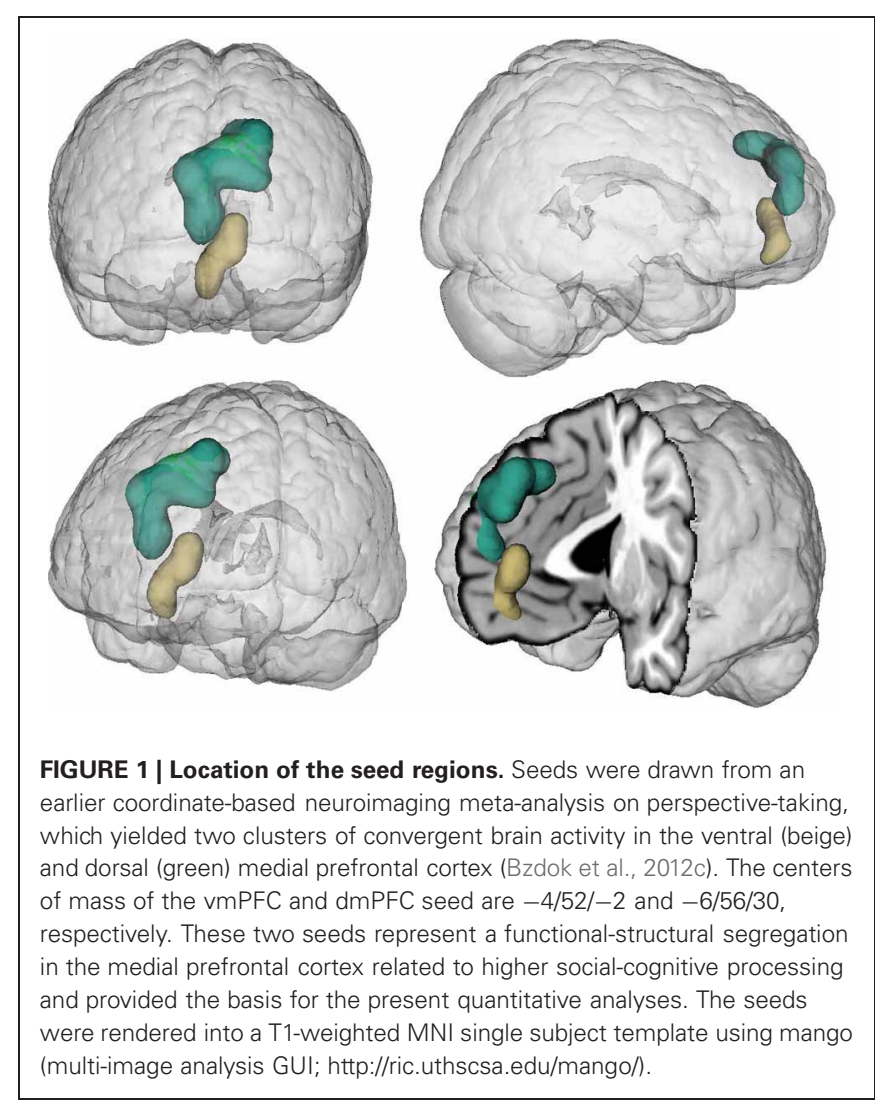




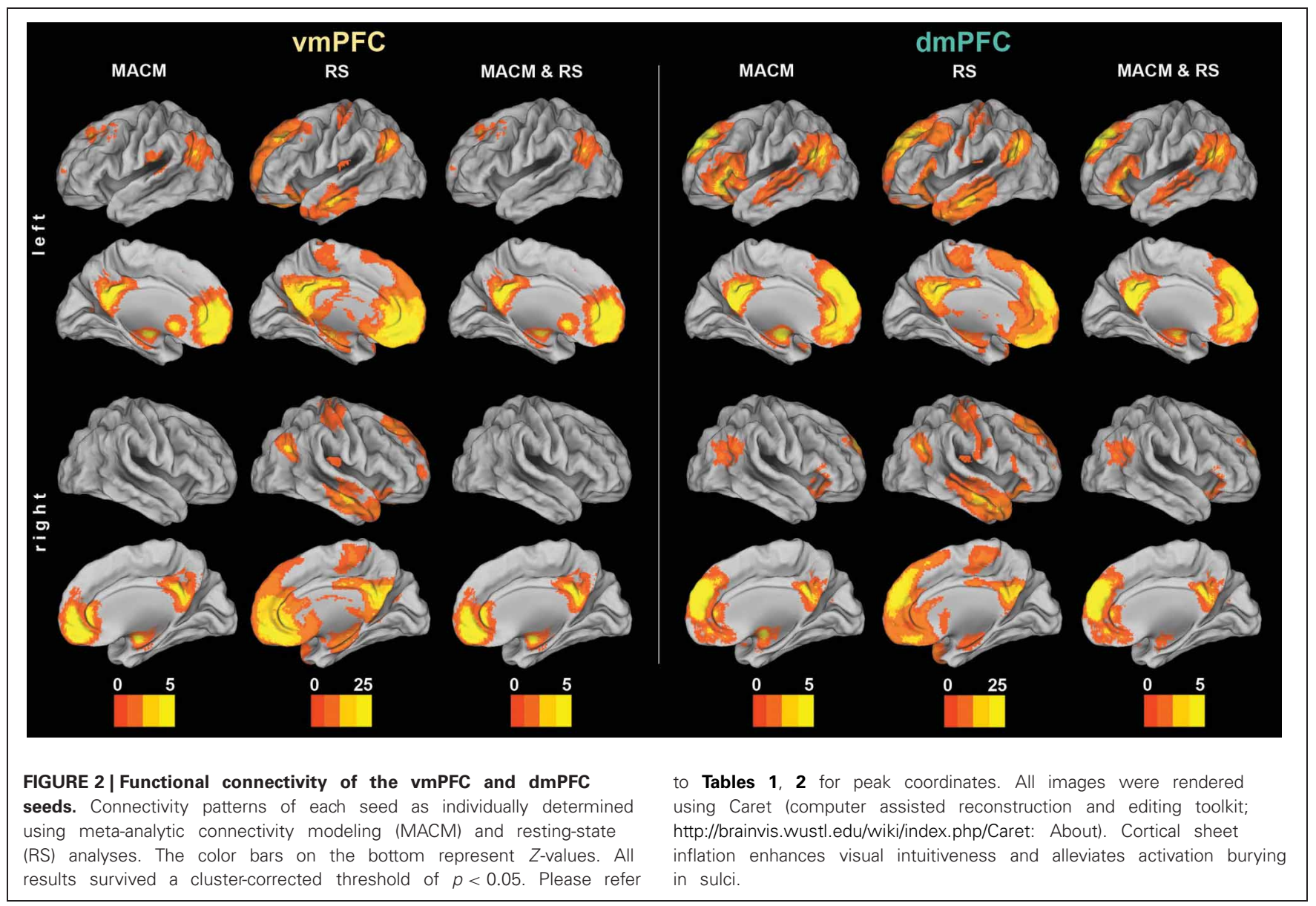

yielded the bilateral vmPFC and dmPFC extending into the ACC, $\mathrm{AM} / \mathrm{HC}$, inferior frontal gyrus (IFG), PCC/RSC, TPJ, and TP, as well as the left anterior insula (AI) and MTG. RS analysis of the dmPFC seed yielded the bilateral vmPFC and dmPFC extending into the ACC, AM, HC, IFG, pMCC, PCC/RSC, Prec, TPJ, MTG, TP, PreG, PoG, pOP, and Cer (not depicted).

\section{FUNCTIONAL CONNECTIVITY: DIFFERENCE ANALYSES BETWEEN SEEDS}

To subsequently determine which brain areas are more strongly coupled with one seed than the other seed, we computed MACM and RS connectivity differences between both seeds (Figure 3). In MACM analyses, the brain areas more strongly coupled with the vmPFC than dmPFC comprised the bilateral vmPFC extending into the ACC, HC (extending into the AM on the right), PCC, and RSC, as well as the left NAc and pOP. In RS analyses, the brain areas more strongly coupled with the vmPFC than dmPFC comprised the bilateral vmPFC, HC, ACC, pMCC, PCC, RSC, Prec, NAc, AI, midbrain/pons, thalamus, visual cortex, posterior lateral parietal cortex, and Cer (not depicted). In MACM analyses, the brain areas more strongly coupled with the dmPFC than vmPFC, in turn, comprised the bilateral PCC, IFG, TPJ, and TP, as well as the left AM and MTG. In RS analyses, the brain areas more strongly coupled with the dmPFC than vmPFC comprised the bilateral orbitofrontal cortex, IFG, MTG, TPJ, TP, PreG, PoG, and Cer (not depicted).

\section{FUNCTIONAL CONNECTIVITY: CROSS-VALIDATION BY CONJUNCTION ANALYSES}

The main goal of our study was the functional connectivity of each seed that is consistent across both types of connectivity analysis (i.e., MACM and RS). Convergence of both approaches should reveal connectivity that is consistently observed across two different states of brain function, that is, during specific task performance (MACM) and in the absence of an externally structured task (RS). To thus test for brain areas congruently connected to either seed across both types of connectivity, we computed the conjunction across the respective MACM and RS analyses (Figure 2 and Tables 1, 2). These conjunction analyses of each seed revealed the same set of brain areas as the respective MACM analysis, except for absent vmPFC connectivity to the operculum.

To test for brain areas more strongly coupled with either seed across MACM and RS analyses, we computed the conjunction across the respective MACM- and RS-based difference analyses (Figure 4, Table 3). Across MACM and RS, brain areas congruently more strongly coupled with the vmPFC than dmPFC comprised the bilateral vmPFC extending into the ACC, HC, PCC, and RSC, as well as the left NAc. Across MACM and RS, brain areas congruently more strongly coupled with the dmPFC 
Table 1 | Functional connectivity of the vmPFC seed.

\begin{tabular}{|c|c|c|c|c|}
\hline Macroanatomical location & $x$ & $y$ & $z$ & $z$ \\
\hline \multicolumn{5}{|l|}{ MACM(vmPFC) } \\
\hline Ventromedial prefrontal cortex & 0 & 52 & -8 & 8. \\
\hline Dorsomedial prefrontal cortex & -12 & 48 & 24 & 3.7 \\
\hline Right amygdala/hippocampus & 24 & -6 & -20 & $6 . £$ \\
\hline Left amygdala/hippocampus & -22 & -14 & -18 & 7. \\
\hline Left nucleus accumbens & -8 & 14 & -6 & $5 . £$ \\
\hline Posterior cingulate cortex & 0 & -42 & 36 & 5.6 \\
\hline Retrosplenial cortex & -2 & -52 & 30 & 6.7 \\
\hline Left temporo-parietal junction & -48 & -66 & 28 & 5.9 \\
\hline Left superior frontal gyrus & -18 & 38 & 46 & 4.5 \\
\hline Left posterior operculum & -60 & -28 & 18 & 6.7 \\
\hline \multicolumn{5}{|l|}{ RS(vmPFC) } \\
\hline Ventromedial prefrontal cortex & -2 & 50 & -10 & 31.9 \\
\hline Dorsomedial prefrontal cortex & 0 & 51 & 17 & 17.6 \\
\hline Right amygdala & 19 & -1 & -20 & 6.7 \\
\hline Left amygdale & -16 & -1 & -21 & 6.6 \\
\hline Right hippocampus & 24 & -20 & -20 & 15.0 \\
\hline Left hippocampus & -30 & -30 & -12 & 12.9 \\
\hline Right nucleus accumbens & 7 & 13 & -11 & 12.1 \\
\hline Left nucleus accumbens & -4 & 12 & -11 & 12.7 \\
\hline Posterior mid-cingulate cortex & 2 & -17 & 39 & 15.0 \\
\hline Posterior cingulate cortex & -2 & -44 & 30 & 21.9 \\
\hline Retrosplenial cortex & 6 & -50 & 22 & 22.5 \\
\hline Precuneus & 3 & -70 & 63 & 15.6 \\
\hline Right temporo-parietal junction & 46 & -68 & 28 & 14.0 \\
\hline Left temporo-parietal junction & -48 & -68 & 38 & 14.6 \\
\hline Right middle temporal gyrus & 62 & -6 & -24 & 14.8 \\
\hline Left middle temporal gyrus & -66 & -14 & -24 & 14.9 \\
\hline Right temporal pole & 42 & 20 & -34 & 9.0 \\
\hline Left temporal pole & -44 & 22 & -40 & 8.4 \\
\hline Right precentral gyrus & 34 & -26 & 48 & 8.6 \\
\hline Left precentral gyrus & -36 & -24 & 54 & 6. \\
\hline Right postcentral gyrus & 38 & -30 & 54 & 7.6 \\
\hline Right posterior operculum & 38 & -22 & 18 & 6.6 \\
\hline Left posterior operculum & -44 & -18 & 18 & 5.4 \\
\hline Right cerebellum & 52 & -66 & -42 & 9.5 \\
\hline Right cerebellum & 6 & -54 & -46 & 11.4 \\
\hline Left cerebellum & -36 & -78 & -38 & 9.5 \\
\hline Left cerebellum & -6 & -56 & -46 & 10. \\
\hline \multicolumn{5}{|l|}{ MACM and RS(vmPFC) } \\
\hline Ventromedial prefrontal cortex & 0 & 52 & -8 & 8.7 \\
\hline Dorsomedial prefrontal cortex & -18 & 38 & 46 & 4.5 \\
\hline Right amygdala/hippocampus & 24 & -8 & -20 & 6.6 \\
\hline Left amygdala/hippocampus & -22 & -14 & -18 & 7. \\
\hline Left nucleus accumbens & -8 & 14 & -6 & 5.8 \\
\hline Posterior cingulate cortex & 0 & -42 & 36 & 5.6 \\
\hline Retrosplenial cortex & -2 & -52 & 30 & 6.7 \\
\hline Left temporo-parietal junction & -48 & -66 & 28 & 5. \\
\hline Left superior frontal gyrus & -18 & 38 & 46 & \\
\hline
\end{tabular}

Table shows coordinates derived from respective cluster peaks $(x, y, z)$ and Z-scores (Z).
Table 2 | Functional connectivity of the dmPFC seed.

\begin{tabular}{llllll}
\hline Macroanatomical location & $x$ & $y$ & $z$ & $z$ \\
\hline MACM(dmPFC) &
\end{tabular}

$\begin{array}{llllll}\text { Ventromedial prefrontal cortex } & -4 & 48 & -12 & 7.5\end{array}$

$\begin{array}{llllll}\text { Dorsomedial prefrontal cortex } & 2 & 56 & 24 & 8.7\end{array}$

$\begin{array}{lllll}\text { Right amygdala/hippocampus } & 20 & -4 & -16 & 5.5\end{array}$

$\begin{array}{llllll}\text { Left amygdala/hippocampus } & -22 & -6 & -18 & 6.9\end{array}$

$\begin{array}{llllll}\text { Right inferior frontal gyrus } & 42 & 26 & -7 & 4.2\end{array}$

$\begin{array}{lllll}\text { Left inferior frontal gyrus } & -48 & 26 & -6 & 8\end{array}$

$\begin{array}{lllll}\text { Left anterior insula } & -32 & 24 & -2 & 4.2\end{array}$

$\begin{array}{lllll}\text { Posterior cingulate cortex } & -4 & -48 & 32 & 8.4\end{array}$

$\begin{array}{lllll}\text { Retrosplenial cortex } & -6 & -56 & 8 & 5.1\end{array}$

$\begin{array}{lllll}\text { Right temporo-parietal junction } & 54 & -70 & 20 & 6.4\end{array}$

$\begin{array}{lllll}\text { Left temporo-parietal junction } & -52 & -68 & 16 & 7.0\end{array}$

$\begin{array}{lllll}\text { Left middle temporal gyrus } & -60 & -36 & 2 & 5.5\end{array}$

$\begin{array}{lllll}\text { Right temporal pole } & 40 & 16 & -20 & 4.4\end{array}$

$\begin{array}{lllll}\text { Left temporal pole } & -36 & 20 & -24 & 4.5\end{array}$

$\begin{array}{lllll}\text { RS(dmPFC) } & 3 & 43 & -23 & 17.7\end{array}$

$\begin{array}{llllll}\text { Dorsomedial prefrontal cortex } & -8 & 56 & 28 & 26.7\end{array}$

Right amygdala

Left amygdale

Right hippocampus

Left hippocampus

Right inferior frontal gyrus

Left inferior frontal gyrus

Posterior mid-cingulate cortex

Posterior cingulate cortex

Retrosplenial cortex

Precuneus

Right temporo-parietal junction

Left temporo-parietal junction

Right middle temporal gyrus

Left middle temporal gyrus

Right temporal pole

Left temporal pole

Right precentral gyrus

Left precentral gyrus

Right postcentral gyrus

Left postcentral gyrus

Right posterior operculum

18

$-20$

$-6$

$-20$

5.0

Left posterior operculum

$-4$

$-20$

7.8

26

$-18$

$-22$

7.7

$\begin{array}{llll}-26 & -20 & -18 & 10.0\end{array}$

$\begin{array}{llll}38 & 30 & -18 & 10.1\end{array}$

$\begin{array}{lrrr}-56 & 29 & 3 & 9.3\end{array}$

$\begin{array}{llll}-2 & -16 & 38 & 14.8\end{array}$

$\begin{array}{llll}-4 & -46 & 34 & 21.5\end{array}$

$\begin{array}{llll}6 & -50 & 24 & 17.8\end{array}$

$\begin{array}{llll}-1 & -64 & 33 & 15\end{array}$

$\begin{array}{llll}54 & -66 & 26 & 14.3\end{array}$

$\begin{array}{llll}-52 & -60 & 26 & 18.3\end{array}$

$\begin{array}{rrrr}-52 & -60 & 26 & 18.3 \\ 62 & -6 & -26 & 15.7\end{array}$

$\begin{array}{rccc}-66 & -8 & -22 & 16.7 \\ 46 & 14 & -36 & 13.1\end{array}$

$\begin{array}{llll}-52 & 10 & -38 & 13.9\end{array}$

$\begin{array}{llll}32 & -28 & 50 & 9.7\end{array}$

$\begin{array}{llll}-30 & -28 & 58 & 8\end{array}$

$\begin{array}{llll}36 & -32 & 56 & 8.7\end{array}$

$\begin{array}{llll}-28 & -30 & 52 & 7.1\end{array}$

$\begin{array}{llll}-40 & -21 & 22 & 4.1\end{array}$

$\begin{array}{lllll}\text { Right cerebellum } & 32 & -80 & -38 & 16.5\end{array}$

$\begin{array}{lllll}\text { Left cerebellum } & -34 & -80 & -38 & 16.0\end{array}$

$\begin{array}{lllll}\text { Right cerebellum } & 8 & -54 & -42 & 13\end{array}$

Left cerebellum

$-6$

$-56$

$-44 \quad 11.2$

\section{MACM and RS(dmPFC)}

Ventromedial prefrontal cortex

$-4$

Dorsomedial prefrontal cortex

Right amygdala/hippocampus

Left amygdala/hippocampus

Right inferior frontal gyrus

Left inferior frontal gyrus

Left anterior insula

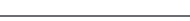


Table 2 | Continued

\begin{tabular}{lrrrr}
\hline Macroanatomical location & $\boldsymbol{x}$ & $\boldsymbol{y}$ & $\boldsymbol{z}$ & $\boldsymbol{Z}$ \\
\hline Posterior cingulate cortex & -4 & -36 & 40 & 3.3 \\
Retrosplenial cortex & -6 & -56 & 8 & 5.1 \\
Right temporo-parietal junction & 54 & -70 & 20 & 6.4 \\
Left temporo-parietal junction & -46 & -74 & 36 & 6.9 \\
Left middle temporal gyrus & -62 & -36 & 2 & 5.2 \\
Right temporal pole & 36 & 18 & -20 & 3.6 \\
Left temporal pole & -36 & 20 & -24 & 4.5 \\
\hline
\end{tabular}

Table shows coordinates derived from respective cluster peaks $(x, y, z)$ and Z-scores (Z).

than vmPFC comprised the bilateral dmPFC, IFG, and TPJ, as well as the left MTG.

Finally, the brain areas congruently coupled with the vmPFC and $\mathrm{dmPFC}$ across both MACM and RS analyses comprised the bilateral vmPFC, frontal pole, AM/HC, and PCC/RSC, as well as the left dmPFC and TPJ.

\section{FUNCTIONAL PROFILING OF THE SEEDS}

After the characterization using connectivity analyses, we also conducted a functional characterization of the vmPFC and dmPFC seeds by determining their significant associations with BrainMap taxonomic categories (Figure 5). For robustness, we focused on taxonomic associations that are significant in both the forward and reverse inference analysis. Forward inference derives brain activity from a psychological term, whereas reverse inference derives a psychological term from brain activity (see Methods section). Accordingly, activity increases in the vmPFC were consistently associated with tasks related to general cognition, social cognition, as well as emotion and reward processing. Note that BrainMap experiments are labeled as related to general cognition mostly if they do not fit into any of the more specific categories. Activity increases in the dmPFC were consistently associated with tasks related to social cognition, theory of mind (i.e., perspective-taking), episodic memory retrieval, as well as processing emotion, also when derived from faces. Note that BrainMap experiments labeled as related to "Episodic Recall" are very likely to be also labeled as "Cognition.Memory.Explicit" rendering these two taxonomic subcategories highly inter-related. When quantifying the taxonomic associations of the seeds relative to each other, the vmPFC (versus dmPFC) was more consistently associated with reward processing and general cognition, while the dmPFC (versus vmPFC) was more consistently associated with (episodic) memory retrieval and theory-of-mind processing. Finally, the taxonomic associations consistent across both vmPFC and dmPFC comprised tasks related to social, emotional, and facial (i.e., "Subjective Emotional Picture Discrimination") processing.

\section{DISCUSSION}

We examined the widely assumed but not directly tested ventrodorsal differentiation of the mPFC in social cognition. This test of segregation was based on a ventral and dorsal mPFC region that are both consistently related to perspective-taking as a prototypical instance of social cognition. The seeds were analyzed using two ways of functional connectivity analyses by independently delineating task-related meta-analytic connectivity modeling (MACM, Eickhoff et al., 2011) and task-unrelated resting-state correlations (RS, Biswal et al., 1995). Additionally, it was tested whether the seeds were differentially associated with psychological terms from BrainMap meta-data using forward and reverse inference. In both MACM and RS analyses, the vmPFC was more strongly connected with the nucleus accumbens (NAc), hippocampus (HC), posterior cingulate cortex (PCC), and retrosplenial cortex (RSC), while the dmPFC was more strongly connected with the inferior frontal gyrus (IFG), temporo-parietal junction (TPJ), and middle temporal gyrus (MTG). In both functional decoding analyses, the vmPFC was selectively associated with reward related tasks, while the dmPFC was selectively associated with perspective-taking and episodic memory retrieval tasks. Importantly, both vmPFC and dmPFC were functionally associated with social, emotional, and facial processing. In sum, the vmPFC was thus more closely connected to limbic and reward-related medial brain areas as well as functionally associated with processing approach- and avoidance-relevant stimuli. In contrast, the dmPFC was more connected to higher associative cortical areas as well as functionally associated with processing mental states and episodic memory.

\section{CONNECTIONAL EVIDENCE FOR THE SEGREGATION BETWEEN THE vmPFC AND dmPFC}

Our convergent connectivity results across MACM and RS analyses derived from the vmPFC and dmPFC seeds agree well with many earlier findings in humans and monkeys. Importantly, the vmPFC and dmPFC have been found to be extensively interconnected in axonal tracing studies in monkeys (Barbas et al., 1999; Saleem et al., 2008), consistent with our results. In the following, we will compare the present connectivity differences between the vmPFC and dmPFC with earlier findings using other connectivity measures in humans and monkeys.

The vmPFC, on the one hand, was more strongly connected to the NAc, HC, PCC, and RSC across two different types of functional connectivity analysis in the present study. Indeed, the vmPFC, but not dmPFC, has been observed to have monosynaptical connections with the ventral striatum (VS, which anatomically includes the NAc) in axonal tracing studies in monkeys (Haber et al., 1995; Ferry et al., 2000). This is consistent with our results and probabilistic diffusion tensor imaging (DTI) tractography in humans and monkeys (Croxson et al., 2005) that quantified the VS to be substantially more likely connected to the vmPFC than dmPFC in both species. This DTI study further estimated the vmPFC to be only slightly more connected to the amygdala (AM) than the dmPFC in monkeys and humans (cf. Bzdok et al., 2012a), in line with the present AM connectivity to both vmPFC and dmPFC. Importantly, roughly balanced connectivity to the AM challenges the frequently proposed vmPFC-dmPFC distinction as emotional versus cognitive. Although monkey tracing studies indicated that the entire medial wall of the prefrontal cortex has amygdalar and cingulate connections, the most ventral part of the $\mathrm{mPFC}$ received strongest connections from most 


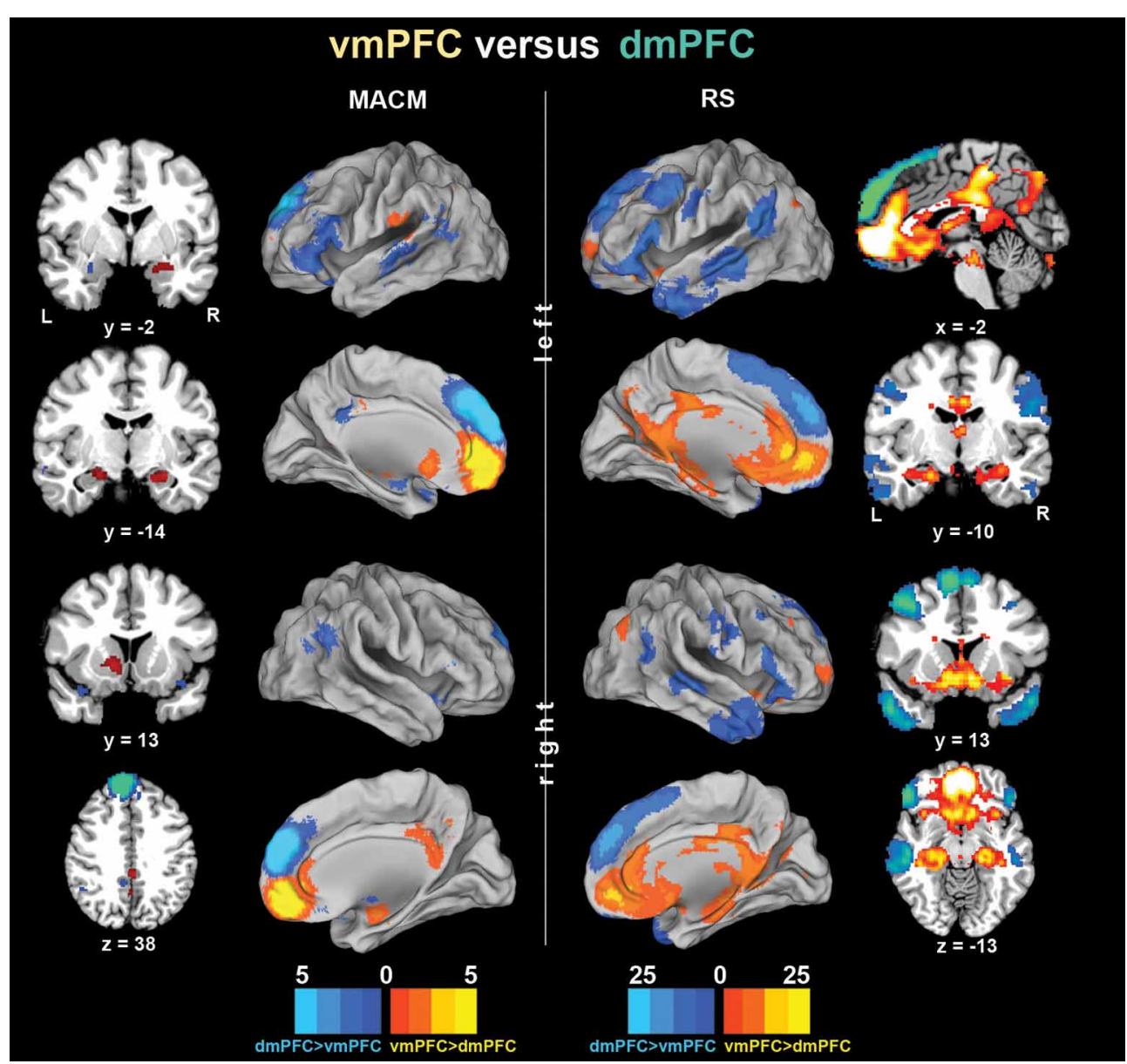

FIGURE 3 | Functional connectivity differences between the vmPFC and dmPFC seeds. Connectivity differences between the seeds individually determined using meta-analytic connectivity modeling (MACM) and resting-state (RS) analyses. The color bars on the bottom represent $Z$-values. All images were rendered using Caret. Coordinates in $\mathrm{MNI}$ space. limbic areas, including the HC (Carmichael and Price, 1995). This concurs with our results and a RS connectivity analysis of the human HC showing more correlation with the vmPFC than dmPFC (Vincent et al., 2006). Additionally, fibers from the medial temporal lobe (including the AM and $\mathrm{HC}$ ) entered the mostly ventral medial partial cortex, including the RSC, as observed using DTI tractography in humans (Greicius et al., 2009). Our results are in line with monkey tracing studies showing that mostly the vmPFC but also dmPFC are directly connected to the PCC (Carmichael and Price, 1995) and RSC (Vann et al., 2009). Conversely, the PCC and RSC (but not the more dorsocaudal precuneus) were mostly connected to limbic regions and the vmPFC in a comparative RS study in monkeys and humans (Margulies et al., 2009). Concluding from previous and present connectivity findings, the VmPFC is preferentially connected with limbic and reward-related medial brain areas.

The dmPFC, on the other hand, was more strongly connected to the TPJ, MTG, and IFG across two different types of functional connectivity analysis in the present study. Using DTI tractography in humans the vmPFC and dmPFC have been observed to be connected to the TPJ, which in turn was connected to the MTG (Caspers et al., 2011). Although we also found convergent functional connectivity of the vmPFC and especially dmPFC to the TPJ, monosynaptical connections from the anterior prefrontal cortex to the TPJ might be absent in monkeys (for discussion, see Caspers et al., 2011). Existence of mPFC-TPJ connectivity in humans is supported by the present results, while our methodological approach cannot distinguish mono- and polysynaptical connections. Our results therefore cannot contribute to the more general question whether direct mPFC-TPJ connections exist in humans but not monkeys. The TPJ and IFG, both relatively more connected to the dmPFC in our study, were also reported to be connected in an axonal tracing study in monkeys (Petrides and Pandya, 2009) and in a DTI study in humans (Frey et al., 2008). Both the vmPFC and dmPFC are further known to have direct connections with the IFG and MTG based on monkey tracing data (Yeterian et al., 2012). In contrast, those two target areas were more strongly connected to the dmPFC in our functional connectivity analyses. Thus, axonal connections between the vmPFC and the IFG and MTG presumably existing in humans 


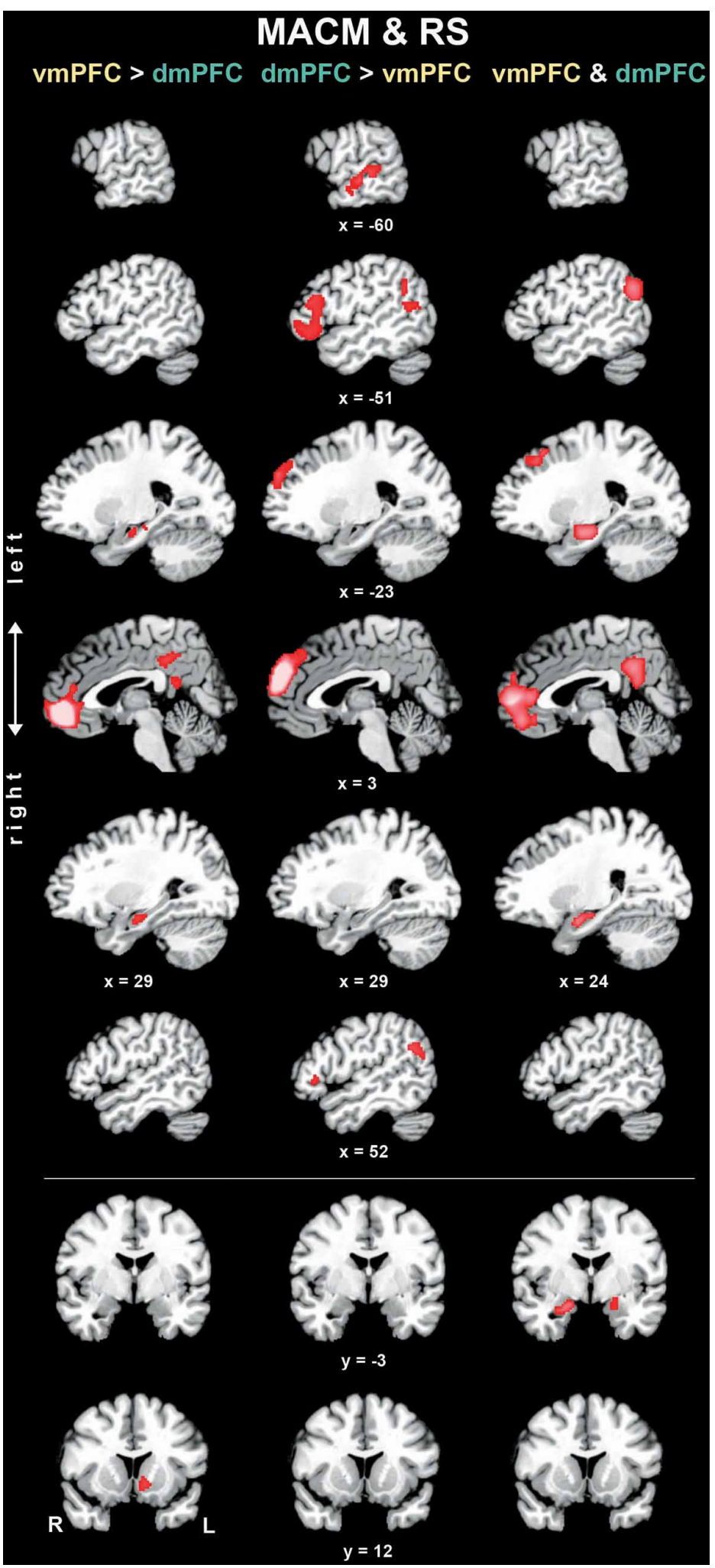

FIGURE 4 | Difference and conjunction analyses based on congruent functional connectivity of the vmPFC and dmPFC seeds. Depicts sagittal and coronal brain slices of areas consistently more strongly coupled (left and middle column) with either seed or congruently coupled with both seeds (right column) across meta-analytic connectivity modeling (MACM) and resting-state (RS) analyses. Please refer to Table $\mathbf{3}$ for activation coordinates. All slices were created using mango (multi-image analysis GUI; http://ric.uthscsa.edu/mango//) on a T1-weighted MNI single subject template. Coordinates in MNI space. $</>$, difference analysis; \&, conjunction analysis; $R$, right; $L$, left. 


\begin{abstract}
Table 3 | Difference and conjunction analyses between functional connectivity of the vmPFC and dmPFC seeds.
\end{abstract}

\begin{tabular}{|c|c|c|c|c|}
\hline Macroanatomical location & $x$ & $y$ & $z$ & $Z$ \\
\hline \multicolumn{5}{|l|}{ MACM \& RS (vmPFC > dmPFC) } \\
\hline Ventromedial prefrontal cortex & 2 & 44 & -18 & 8.1 \\
\hline Right hippocampus & 30 & -10 & -22 & 3.0 \\
\hline Left hippocampus & -20 & -14 & -18 & 2.7 \\
\hline Left nucleus accumbens & -8 & 18 & -4 & 4.6 \\
\hline Posterior cingulate cortex & 4 & -38 & 38 & 3.2 \\
\hline Retrosplenial cortex & 2 & -46 & 18 & 2.3 \\
\hline Retrosplenial cortex & -12 & -58 & 16 & 2.9 \\
\hline \multicolumn{5}{|l|}{ MACM \& RS (vmPFC $<$ dmPFC) } \\
\hline Dorsomedial prefrontal cortex & 2 & 58 & 12 & 8.1 \\
\hline Right inferior frontal gyrus & 52 & 28 & 0 & 2.1 \\
\hline Left inferior frontal gyrus & -42 & 40 & -10 & 3.4 \\
\hline Left inferior frontal gyrus & -50 & 28 & 18 & 3.3 \\
\hline Right temporo-parietal junction & 56 & -54 & 26 & 3.8 \\
\hline Left temporo-parietal junction & -50 & -52 & 30 & 3.0 \\
\hline Left temporo-parietal junction & -50 & -56 & 10 & 2.5 \\
\hline Left middle temporal gyrus & -60 & -22 & -8 & 3.7 \\
\hline \multicolumn{5}{|l|}{ MACM \& RS (vmPFC \& dmPFC) } \\
\hline Ventromedial prefrontal cortex & -4 & 48 & -12 & 7.5 \\
\hline Frontal pole & -4 & 56 & 2 & 8.4 \\
\hline Left dorsomedial prefrontal cortex & -18 & 38 & 46 & 4.5 \\
\hline Right amygdala/hippocampus & 20 & -4 & -18 & 5.3 \\
\hline Left amygdala/hippocampus & -24 & -12 & -20 & 5.8 \\
\hline Posterior cingulate cortex/retrosplenial cortex & -2 & -52 & 30 & 6.7 \\
\hline Left temporo-parietal junction & -48 & -66 & 28 & 6.0 \\
\hline
\end{tabular}

Table shows coordinates derived from respective cluster peaks ( $x, y, z)$ and Z-scores (Z). < and > denote difference analyses, while \& denotes conjunction analysis.

might be less important for social-cognitive processing than those of the dmPFC. Similarly, although DTI tractography in humans (Greicius et al., 2009) and axonal tracing in monkeys (Cavada and Goldman-Rakic, 1989) have identified fiber bundles connecting the dmPFC with the more dorsal and posterior medial parietal cortex (precuneus), this was not reflected by our functional connectivity results. Concluding from previous and present connectivity findings, the $\mathrm{dmPFC}$ is preferentially connected with high association and heteromodal cortical areas of the lateral frontal, temporal, and parietal lobe. More globally, most of the present functional connectivity findings of the human vmPFC and dmPFC concur very well with knowledge describing structural connectivity in the monkey and human brain. However, our results also show that known axonal connections between the mPFC and other parts of the brain are not always reflected in functional connectivity analyses.

\section{INTEGRATIVE SEGREGATION BETWEEN THE vmPFC AND dmPFC}

After discussing the connectivity differences between the vmPFC and dmPFC, we will now discuss the previously proposed functional properties of their respective connectivity targets (cf. Fuster, 2001). The vmPFC was more connected to the NAc, HC, PCC, and RSC. The NAc is thought to be linked to reward mechanisms that may not only modulate motivated behavior towards basic survival needs, such as food and sex, but also towards salient social cues (cf. Kampe et al., 2001; Cardinal et al., 2002; Walter et al., 2005; Schilbach et al., 2010). Neuroimaging research indeed ascribed complex reward functions to the NAc, such as the evaluation of reward expectancy in social, monetary, or drug rewards (Schultz et al., 1997; Kampe et al., 2001; Rademacher et al., 2010; Bzdok et al., 2011). The HC, in turn, is well known to be involved in memory and spatial navigation in animals and humans (von Bechterew, 1900; Scoville and Milner, 1957; O'Keefe and Dostrovsky, 1971; Maguire et al., 2000). As to the PCC and RSC, electrophysiological research in animals implicated the PCC in strategic selection (Pearson et al., 2009), risk assessment (McCoy and Platt, 2005), and outcome-contingent behavioral modulation (Hayden et al., 2008), while the RSC was implicated in navigation and approach-avoidance behavior (Vann et al., 2009). Considering only the previously reported functional properties of the here more strongly connected nodes, the vmPFC can be assumed to integrate a subnetwork (i.e., the brain areas relatively more connect to the vmPFC, excluding the vmPFC seed itself) modulating online approach-avoidance behavior by memory-informed reward and risk estimation of self-relevant environmental stimuli.

In contrast, the dmPFC was more connected to the IFG, TPJ, and MTG. As these subnetwork nodes (i.e., the brain areas relatively more connected to the $\mathrm{dmPFC}$, excluding the $\mathrm{dmPFC}$ seed itself) are highly associative and heteromodal, there is less clarity and agreement about their discrete functional contributions. As a side note, the mere difference in the association level between the vmPFC's and dmPFC's subnetworks already indicates functional segregation (Mesulam, 1998). Moreover, the entire set of dmPFC-linked regions is well known to concomitantly increase and decrease metabolic activity as a cohesive unit, as lateral components of the so-called "default mode network" (Gusnard et al., 2001; Laird et al., 2009b; Spreng et al., 2009; Mar, 2011; Bzdok et al., 2012c; Schilbach et al., 2012). In fact, it is interesting to note that the vmPFC is more strongly connected to medial components of the default mode network (i.e., HC, PCC, RSC), whereas the dmPFC is more strongly connected to its lateral components (i.e., IFG, TPJ, and MTG). This dmPFC subnetwork was repeatedly related to self-focused reflection (Andrews-Hanna et al., 2010), contemplation of others' (Mar, 2011) and one's own (Lombardo et al., 2009) mental states, mental navigation of the body in space (Maguire et al., 1997), semantic processing (Binder et al., 2009), as well as scene construction processes when envisioning past, fictitious, and future events (Hassabis et al., 2007; Spreng et al., 2009; Bzdok et al., 2013). Interestingly, the neuroimaging studies related to processing semantic information (Binder et al., 2009), autobiographical (Spreng et al., 2009) and fictitious (Hassabis et al., 2007) events observed neural activity increases in both the vmPFC and dmPFC, although the respective neural networks resemble much more the dmPFC (rather than vmPFC) subnetwork. The conjunction of previous and present findings suggests that the dmPFC integrates a network involved in self- or otherrelated, largely sensory-independent, highly abstract (hence, less 


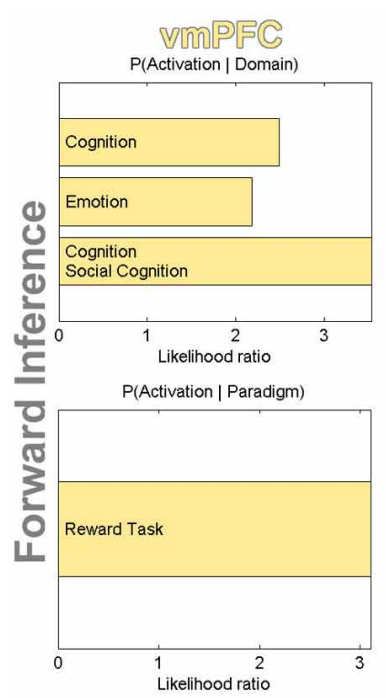

$P($ Domain | Activation)
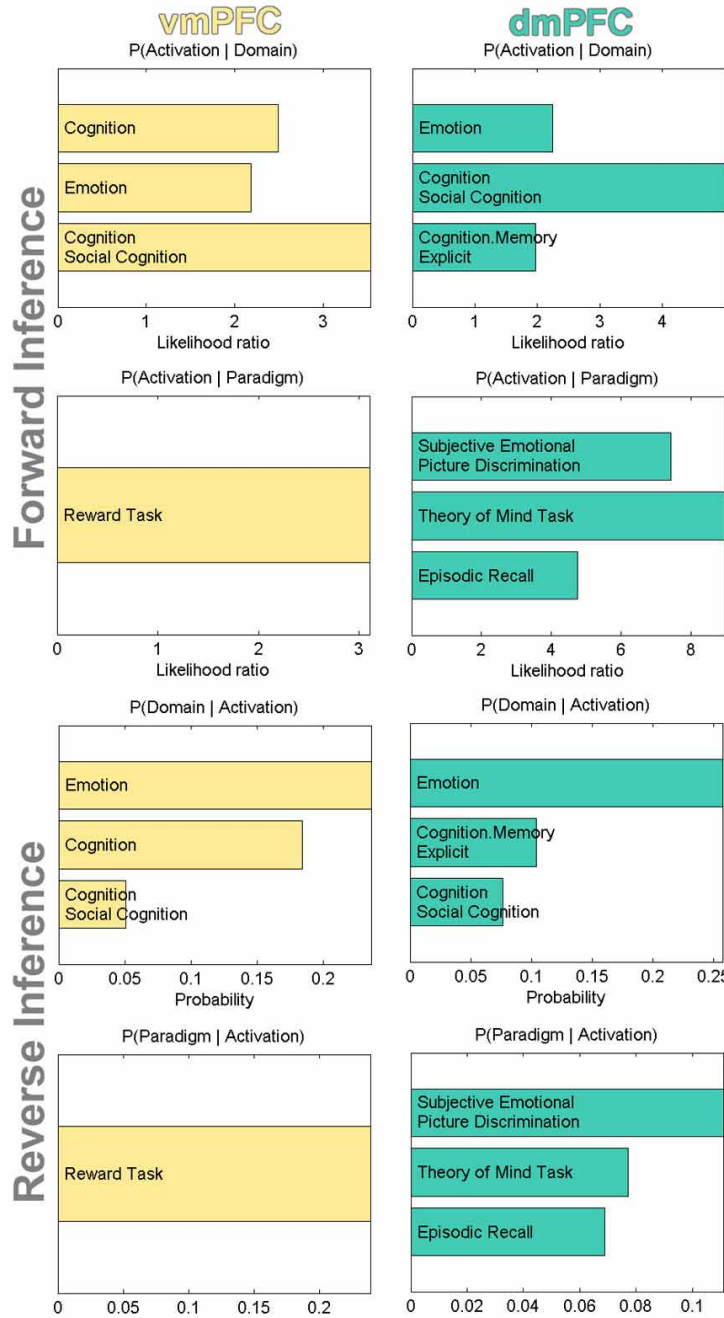

P(Domain | Activation)

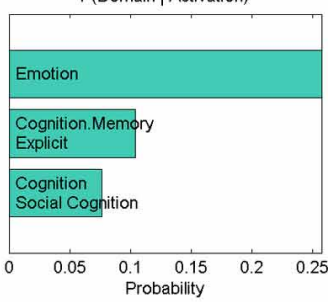

P(Paradigm | Activation)

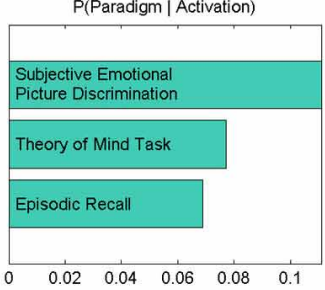

FIGURE 5 | Functional profiling of the vmPFC and dmPFC seeds. Significant associations with psychological terms (behavioral domains and paradigm classes) from BrainMap meta-data. Functional profiling was performed as individual, difference, and conjunction analysis.

Forward inference determines above-chance brain activity given the
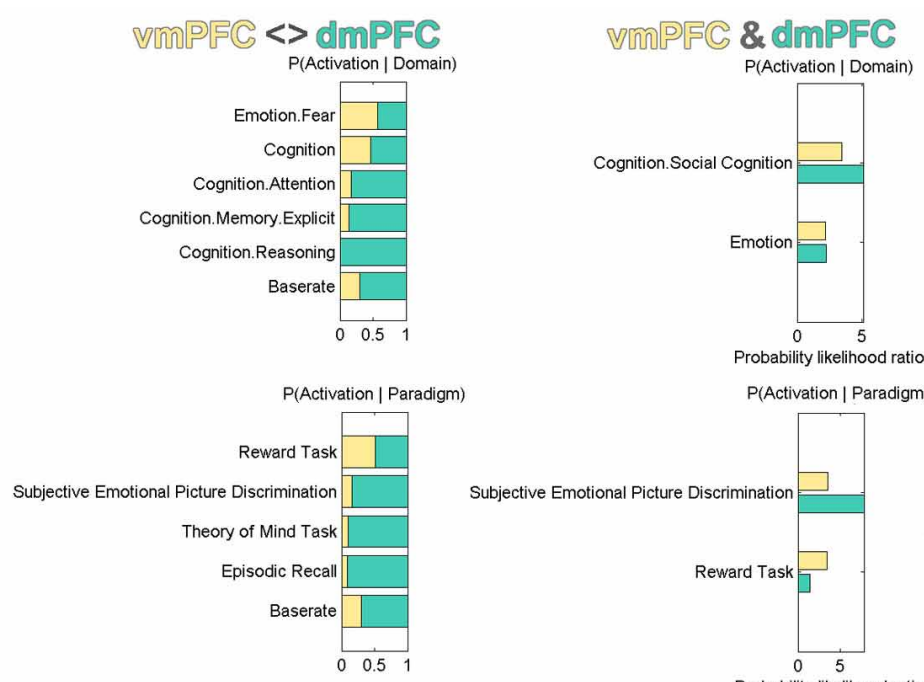

Probability likelihood ratio
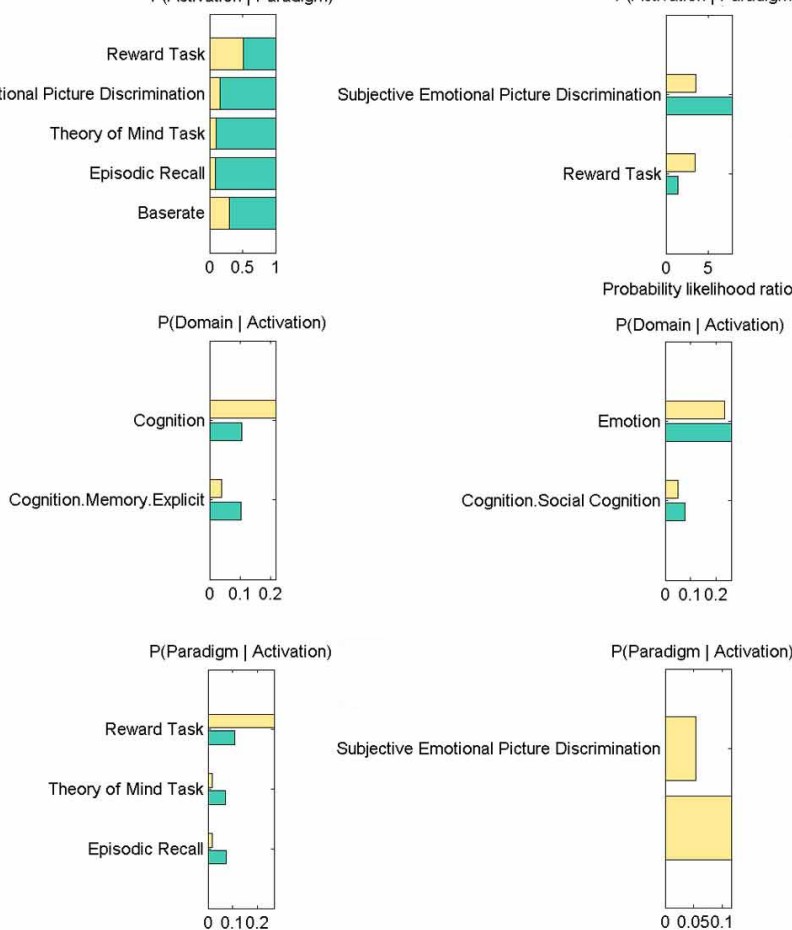

presence of a psychological term, while reverse inference determines the above-chance probability of a psychological term given observed brain activity. The base rate denotes the general probability of finding BrainMap activation in the seed. The $x$-axis indicates relative probability values. tangible) processes across time, space, and content domains. Importantly, the previously proposed vmPFC-dmPFC distinction as outcome-oriented versus goal-oriented is challenged by our results that support outcome-oriented vmPFC processing but not specifically goal-oriented dmPFC processing. It is also important to note that both the vmPFC and dmPFC are closely related to memory retrieval as indicated by converging functional connectivity (across MACM and RS) to the HC. However, the memory-retrieved information appears to be bound with less complex neural processes in the vmPFC versus dmPFC as indicated by functional association with, for instance, less complex reward processes versus more complex perspective-taking processes.

Additionally, the here identified subnetworks belonging to the vmPFC and dmPFC corroborate an earlier hierarchical clustering analysis based on an fMRI study (Andrews-Hanna et al., 2010). In particular, seed regions were derived from comparing future versus present self-related thinking in bidirectional fMRI contrasts. Subsequent resting-state analyses of these seed regions allowed clustering into a vmPFC-associated subnetwork, including the HC and PCC/RSC, and a dmPFCassociated subnetwork, including the TPJ and MTG. The fMRI data then related, respectively the vmPFC and dmPFC subnetworks to thinking about present and future self, in line with our functional decoding results. Put differently, the vmPFC might be more closely associated with orchestrating adapted behavior by bottom-up-driven processing of "what matters now", which might be top-down modulated by more dmPFC subserved higher reflective and hypothetical processing. 


\section{MORPHOLOGICAL EVIDENCE FOR THE SEGREGATION BETWEEN THE vmPFC AND dmPFC}

It may be instructive to acknowledge the relationship between the present findings on social cognition in mPFC subregions and the recently increasing evidence for the "social brain" that might have coevolved with the complexity of social relationships (Jolly, 1966; Humphrey, 1978; Byrne and Whiten, 1988; Dunbar, 1998; Dunbar and Shultz, 2007). Most importantly, independent whole-brain analyses from structural neuroimaging studies related the gray-matter volume (GMV) of the vmPFC to indices of social competence and social network complexity in both humans and monkeys (Lebreton et al., 2009; Powell et al., 2010; Lewis et al., 2011; Sallet et al., 2011). To our knowledge, none of these four correlations have been found yet for the dmPFC. Consequently, vmPFC, rather than $\mathrm{dmPFC}$, anatomy appears to predict an individual's social behavioral dispositions and social network properties, although we found both regions to be congruently associated with social, emotional, and facial processing.

Such brain-behavior correlations in humans were also shown for the brain areas preferentially connected to the vmPFC or $\mathrm{dmPFC}$ in the present analysis. As to the vmPFC subnetwork, the GMV of the vmPFC and VS correlated with indices of social reward attitudes and behavior (Lebreton et al., 2009), concurring with vmPFC's relation to the NAc and reward-related tasks. Additionally, the GMV of the entorhinal cortex (connectionally and functionally closely coupled with the HC) correlated with social network size (Kanai et al., 2012), concurring with vmPFC's connectivity to the HC. Further, vmPFC and PCC/Prec GMV correlated with social network size (Lewis et al., 2011), concurring with vmPFC's stronger connectivity to the PCC. As to the dmPFC subnetwork, the GMV of the TPJ and MTG correlated with social network size (Kanai et al., 2012), while the GMV of the TPJ and IFG correlated with perspective-taking competence (Lewis et al., 2011). Moreover, the GMV of the amygdala, connected to both vmPFC and dmPFC, correlated negatively with social phobia (Irle et al., 2010) and positively with social network size (Bickart et al., 2010).

The conjunction of these recent brain-behavior correlations and the present results allow several conclusions. With respect to our seeds, inter-individual differences in social skills or social networks were most often related to morphological differences in the human and monkey vmPFC, in stark contrast to the dmPFC. With respect to the seeds' subnetworks, the reported brain-behavior correlations were roughly equally related to the more vmPFC or dmPFC connected brain areas. With respect to the type of social variable, morphological differences related to either social skills or networks do not seem to be preferentially associated with the more vmPFC or dmPFC connected brain areas.

The conclusions prompt the hypothesis that the dmPFC subserves a domain-independent neural process important for, but not specific to, social cognition. Indeed, the present results support the dmPFC's possible involvement in domain-overarching computational mechanisms given its connections to highly associative brain areas and functionally relation to different complex psychological processes.
Although vmPFC and dmPFC were associated with social, emotional, and facial processing, the dmPFC probably processes these types of information on a higher level of abstraction.

\section{NEUROPSYCHOLOGICAL EVIDENCE FOR THE SEGREGATION BETWEEN THE vmPFC AND dmPFC}

The conclusions derived from our findings are corroborated by brain lesion data. Consistent with the functional association of the vmPFC with reward processing as well as with a role in predominantly self-related behavior guided by stimulus evaluation and reward-learning, a voxel-based lesion-symptom mapping (VLSM) study in 344 neurological patients demonstrated functional-anatomical specificity of the vmPFC for value-based decision-making (Gläscher et al., 2012). However, vmPFC damage in humans also impairs an array of predominantly otherrelated socio-emotional processes. More specifically, consistent with vmPFC's connectivity to both the limbic system and the dmPFC, vmPFC lesions appear to impair the integration of (other-related) higher social, basic emotional, and facial processes, rather than any of these three classes of neural processes per se (Bzdok et al., 2012b). This is indicated by (1) disrupted emotion recognition from faces (Hornak et al., 1996) despite intact face recognition (Shamay-Tsoory et al., 2005; Monte et al., 2012), (2) sociopathic behavior in every-day life (Blair and Cipolotti, 2000) despite intact abstract reflection of social phenomena (Saver and Damasio, 1991; Damasio, 1996; Young et al., 2010), (3) disrupted affective but not cognitive perspective-taking (Stone et al., 1998; Stuss et al., 2001; Shamay-Tsoory et al., 2006; Shamay-Tsoory and Aharon-Peretz, 2007), (4) disrupted perspective-taking-based empathy despite intact simpler affective empathy (Shamay-Tsoory et al., 2009), and (5) reduced emotional impact on moral judgments (Koenigs et al., 2007; Young et al., 2010).

Put differently, vmPFC lesion might alter the subset of abstract social processes that require vmPFC-mediated relay of emotional limbic information to the dmPFC, consistent with our connectional and functional results. Indeed, faux detection (i.e., abstract social processing involving emotion processing) is impaired after damage to either the amygdalae (Stone et al., 2003) or the vmPFC (Gregory et al., 2002). The conjunction of previous lesion reports and present results therefore suggests that the vmPFC interweaves more emotional processes (mainly subserved by the limbic system) and more ambiguous social thought (probably subserved by the dmPFC) to shape self- and otherrelated behavioral responses to sensory events in social cognition (Shamay-Tsoory and Aharon-Peretz, 2007; Bzdok et al., 2012b).

Juxtaposing the effects of vmPFC and dmPFC lesions in humans is impeded by the scarcity of circumscribed dmPFC lesions (cf. Mochizuki and Saito, 1990; Duffy and Campbell, 1994; Wilson et al., 2010). Although quite heterogeneous, the few available dmPFC-linked lesion findings consolidate the here derived segregation within the $\mathrm{MPFC}$ as a function of reliance on bottom-up versus top-down processing pathways. First, the dmPFC subnetwork was normally recruited in congenitally blind individuals engaged in perspective-taking (Bedny 
et al., 2009). Therefore, complete lack of visual input does not appear to alter functioning of this high-level area, contrarily to low-level visual cortices. Second, a VLSM study on disturbed sleep (i.e., a state of mind independent of sensory stimulation but dependent on internally generated information) exclusively identified the dmPFC (Koenigs et al., 2010). Third, another VLSM study exclusively related the IFG and TPJ, both more strongly connected to the dmPFC in our study, to inner speech (Geva et al., 2011). Taken together, in individuals with an intact central nervous system, the vmPFC versus dmPFC are probably involved in predominantly bottom-up versus top-down mediated processing of social information.

\section{NEUROIMAGING EVIDENCE FOR THE SEGREGATION BETWEEN THE vmPFC AND dmPFC}

Following the observed functional associations with fear and reward, the vmPFC is likely to process not only external but also visceral stimuli. Indeed, measurements of task-induced brain activity changes in humans confirm our functional decoding results by relating the vmPFC to monitoring others' (Lotze et al., 2007) and one's own (Lane et al., 1997; Phan et al., 2004) emotional responses, that is, other's (external) emotional reactions and one's own (visceral) arousal. Such real or imagined bodily states, believed to be represented in the vmPFC, probably operate as a bioregulatory disposition governing cognition and decision making (Damasio, 1996; Nauta, 1971), in line with the vmPFC's functional association with general cognition and reward processing. An fMRI study, for instance, reported specific vmPFC activity increases during other-initiated joint attention, suggesting representation of the motivational significance of social cues (Schilbach et al., 2010). Consistent with our line of interpretation, vmPFC versus dmPFC activity was moreover shown to reflect actually choice-relevant versus modeled, choice-irrelevant value in a computational fMRI study (Nicolle et al., 2012). The conjunction of previous functional neuroimaging findings and our functional profiling data consolidate the vmPFC's role in processing self- and other-related visceroaffective and motivational information as a guide in ongoing social behavior.

Moreover, the vmPFC and dmPFC were both significantly associated with social, emotional, and facial processing in the present study. This indicates that the vmPFC and dmPFC are not functionally dissociable by selective involvement in social, emotional, or facial processing, although this is frequently proposed. However, the dmPFC, but not vmPFC, was congruently associated with more complex social-cognitive tasks across forward and reverse functional decoding, including perspectivetaking and episodic memory retrieval. While the former imposes an other-focused mind set, the latter inherently entails a selffocused mind set (obviously, one can only recall scenes from one's own personal experience). Quantitative functional profiling of the dmPFC therefore indicates that the dmPFC is involved in both self- and other-oriented processing, analogous to the vmPFC. Importantly, the frequently proposed vmPFCdmPFC distinction as self versus other is challenged by our conclusions.
In particular, consistent with present functional decoding, neural activity in the dmPFC, rather than vmPFC, has been consistently interpreted to underlie inference, representation, and assessment of one's own and others' mental states in functional neuroimaging research (Gusnard et al., 2001; Gallagher and Frith, 2003; Amodio and Frith, 2006; Gilbert et al., 2006; Ochsner, 2008; Van Overwalle, 2009; Bzdok et al., 2012b; Moran et al., 2012). For instance, dmPFC (but not vmPFC) activity was related to the proficiency decline of mental state inference in elderly (Moran et al., 2012), cognitive regulation of one's own emotional states (Ochsner et al., 2004b) and inference of another person's emotional states (Ochsner et al., 2004a), as well as self-reported (Wagner et al., 2011) and experimentally measured (Zaki et al., 2009) proficiency in emotional state inference. Notably, such selfand other-related conceptualizations cannot be made based on sensory information or general knowledge about the physical world (cf. Premack and Woodruff, 1978; Leslie, 1987; Carruthers, 2009). Thus, mental state inference necessarily relies on the generation of probabilistic internal information. Supported by dmPFC's functional association with episodic memory retrieval, such prima vista non-mnemonic construction processes are likely to be subserved by the neural network underlying retrieval of past and imagination of future scenes as indicated by recent neuroimaging experiments and meta-analyses (Schacter et al., 2007; Spreng et al., 2009; Andrews-Hanna et al., 2010; Rabin et al., 2010; Bzdok et al., 2012c). Constructing such probabilistic scenes is further believed to necessarily drawn on semantic knowledge retrieval (Binder et al., 1999; Bar, 2007; Suddendorf and Corballis, 2007; Carruthers, 2009; Bzdok et al., 2012c). This would be in line with left lateralization of the dmPFC subnetwork typical of semantic processing (Binder et al., 2009). The conjunction of previous functional neuroimaging findings and present neuroinformatic findings congruently characterizes the dmPFC as a "mental sketchpad" (Goldman-Rakic, 1996) potentially implicated in modeling and binding plausible self- and other-related scenarios instructed by semantic concepts in social cognition. Again, such sensory-independent de novo generation of meaning representations can only be expected from highly associative, integrative brain areas such as those of the dmPFC subnetwork (Mesulam, 1998), as opposed to the vmPFC subnetwork.

\section{CONCLUSION}

Although the human mPFC is neither uniquely nor solely devoted to social cognition, its central role in navigating the interpersonal space is probably one of the most often replicated findings in functional neuroimaging research. However, the strength of cognitive neuroscience comes from investigating an identical phenomenon from various conceptual and methodological perspectives (cf. Feyerabend, 1975). We therefore re-examined the widely assumed ventrodorsal functional segregation of the mPFC in social cognition in a bottom-up approach and integrated the ensuing results with different literatures. As a result of this, we comprehensively characterized both the vmPFC and dmPFC as relevant for self- and other-focused as well as social, emotional, and facial processing. More specifically, the vmPFC subserves predominantly non-ambiguous subjective-value-related evaluative processes driven by bottom-up pathways, whereas the 
dmPFC subserves predominantly ambiguous amodal metacognitive processes driven by top-down pathways. These conclusions amend a number of earlier accounts on the division of labor between ventral and dorsal aspects of the mPFC in social cognition. Ultimately, the integration of external stimulation and internal generation driven processes in the $\mathrm{mPFC}$ is a part of what determines social behavior.

\section{REFERENCES}

Amodio, D. M., and Frith, C. D. (2006). Meeting of minds: the medial frontal cortex and social cognition. Nat. Rev. Neurosci. 7, 268-277. doi: 10.1038/nrn1884

Andrews-Hanna, J. R., Reidler, J. S., Sepulcre, J., Poulin, R., and Buckner, R. L. (2010). Functional-anatomic fractionation of the brain's default network. Neuron 65, 550-562. doi: 10.1016/j.neuron.2010.02.005

Ashburner, J., and Friston, K. J. (2005). Unified segmentation. Neuroimage 26, 839-851. doi: 10.1016/j.neuroimage.2005.02.018

Bar, M. (2007). The proactive brain: using analogies and associations to generate predictions. Trends Cogn. Sci. 11, 280-289. doi: 10.1016/j.tics.2007.05.005

Barbas, H., Ghashghaei, H., Dombrowski, S. M., and RempelClower, N. L. (1999). Medial prefrontal cortices are unified by common connections with superior temporal cortices and distinguished by input from memory-related areas in the rhesus monkey. J. Comp. Neurol. 410, 343-367.

Bedny, M., Pascual-Leone, A., and Saxe, R. R. (2009). Growing up blind does not change the neural bases of Theory of Mind. Proc. Natl. Acad. Sci. U.S.A. 106, 11312-11317.

Bickart, K. C., Wright, C. I., Dautoff, R. J., Dickerson, B. C., and Barrett, L. F. (2010). Amygdala volume and social network size in humans. Nat Neurosci.14, 163-164. doi: 10.1038/nn.2724

Binder, J. R., Desai, R. H., Graves, W. W., and Conant, L. L. (2009). Where is the semantic system? A critical review and meta-analysis of 120 functional neuroimaging studies. Cereb. Cortex. 19, 2767-2796. doi: 10.1093/cercor/bhp055

Binder, J. R., Frost, J. A., Hammeke, T. A., Bellgowan, P. S., Rao, S. M., and Cox, R. W. (1999). Conceptual processing during the conscious resting state: a functional MRI study. J. Cogn. Neurosci. 11, 80-93.

Biswal, B., Yetkin, F. Z., Haughton, V. M., and Hyde, J. S. (1995). Functional connectivity in the motor cortex of resting human brain using echo-planar MRI. Magn. Reson. Med. 34, 537-541.

Blair, R. J., and Cipolotti, L. (2000). Impaired social response reversal. A case of 'acquired sociopathy'. Brain 123 (Pt 6), 1122-1141. doi: 10.1093/brain/123.6.1122

Broca, P. (1865). Sur la faculté du et Memoires de la Societé d'Anthropologie de Paris 6, 377-393.

Burgess, P. W., Gilbert, S. J., Okuda, J., and Simons, J. S. (2006). "Rostral prefrontal brain regions (area 10). A gateway between inner thought and the external world?" in Disorders of Volition, eds W. Prinz and N. Sebanz (Cambridge: MIT Press).

Byrne, R. W., and Whiten, A., (eds.) Social Expertise and the Evolution of Intellect in Monkeys, Apes, and Humans. Oxford: Oxford University Press.

Bzdok, D., Laird, A., Zilles, K., Fox, P. T., and Eickhoff, S. B. (2012a). An investigation of the structural, connectional and functional sub-specialization in the human amygdala. Hum. Brain Mapp. doi: 10.1002/hbm.22138. (in press).

Bzdok, D., Langner, R., Hoffstaedter, F., Turetsky, B. I., Zilles, K., and Eickhoff, S. B. (2012b). The modular neuroarchitecture of social judgments on faces. Cereb. Cortex. 22, 951-961. doi: 10.1093/cercor/bhr166

Bzdok, D., Schilbach, L., Vogeley, K. Schneider, K., Laird, A. R., Langner, R., et al. (2012c). Parsing the neural correlates of moral cognition: ALE meta-analysis on morality, theory of mind, and empathy. Brain 10.1007/s00429-012-0380-y

Bzdok, D., Langner, R., Caspers, S., Kurth, F., Habel, U., Zilles, K., et al. (2011). ALE meta-analysis on facial judgments of trustworthiness and attractiveness. Brain. Struct. Funct. 215, 209-223. doi: 10.1007/s00429010-0287-4

Bzdok, D., Langner, R., Schilbach, L., Jakobs, O., Roski, C., Caspers, S., et al. (2013). Characterization of the temporo-parietal junction by combining data-driven parcellation, language articulaire. Bulletins (1988). Machiavellian Intelligence: Struct. Funct. 217, 783-796. doi:

\section{ACKNOWLEDGMENTS}

This study was supported by the National Institute of Mental Health (R01-MH074457, Peter T. Fox, Angela R. Laird, Simon B. Eickhoff), the Helmholtz Initiative on Systems-Biology "The Human Brain Model” (Simon B. Eickhoff), and the German National Academic Foundation (Danilo Bzdok). The authors declare no conflict of interest.

complementary connectivity analyses, and functional decoding. Neuroimage (in press).

Cardinal, R. N., Parkinson, J. A., Hall, J., and Everitt, B. J. (2002). Emotion and motivation: the role of the amygdala, ventral striatum, and prefrontal cortex. Neurosci. Biobehav. Rev. 26, 321-352. doi: 10.1016/S0149-7634(02)00007-6

Carmichael, S. T., and Price, J. L. (1995). Limbic connections of the orbital and medial prefrontal cortex in macaque monkeys. $J$. Comp. Neurol. 363, 615-641. doi: $10.1002 /$ cne. 903630408

Carruthers, P. (2009). How we know our own minds: the relationship between mindreading and metacognition. Behav. Brain. Sci. 32, 1-62.

Caspers, S., Eickhoff, S. B., Rick, T. von Kapri, A., Kuhlen, T., Huang, R., et al. (2011). Probabilistic fibre tract analysis of cytoarchitectonically defined human inferior parietal lobule areas reveals similarities to macaques. Neuroimage. 58, 362-380. doi: 10.1016/j.neuroimage.2011.06.027

Cavada, C., and Goldman-Rakic, P. S. (1989). Posterior parietal cortex in rhesus monkey: II. Evidence for segregated corticocortical networks linking sensory and limbic areas with the frontal lobe. J. Comp. Neurol. 287, 422-445.

Cieslik, E. C., Zilles, K., Caspers, S. Roski, C., Kellermann, T. S., Jakobs, O., et al. (2012). Is there "One" DLPFC in cognitive action control? Evidence for heterogeneity from coactivation-based parcellation. Cereb Cortex. doi: 10.1093/cercor/bhs256. (in press).

Contreras, J. M., Banaji, M. R., and Mitchell, J. P. (2012). Dissociable neural correlates of stereotypes and other forms of semantic knowledge. Soc. Cogn. Affect. Neurosci. 7 , 764-770. doi: 10.1093/scan/nsr053

Croxson, P. L., Johansen-Berg, H., Behrens, T. E., Robson, M. D., Pinsk, M. A., Gross, C. G., et al. (2005). Quantitative investigation of connections of the prefrontal cortex in the human and macaque using probabilistic diffusion tractography. J. Neurosci. 25, 8854-8866.
Damasio, A. R. (1996). The somatic marker hypothesis and the possible functions of the prefrontal cortex. Philos. Trans. R. Soc. Lond. B Biol. Sci. 351, 1413-1420. doi: 10.1098/rstb.1996.0125

den Ouden, H. E., Frith, U., Frith, C., and Blakemore, S. J. (2005). Thinking about intentions. Neuroimage. 28, 10. doi: 10.1016/j.neuroimage.2005.05.001

Duffy, J. D., and Campbell, 3rd. J. J. (1994). The regional prefrontal syndromes: a theoretical and clinical overview. $J$. Neuropsychiatry. Clin. Neurosci. 6, 379-387.

Dunbar, R. I. M. (1998). The social brain hypothesis. Evol. Anthropol. 6, 178-190.

Dunbar, R. I. M., and Shultz, S. (2007). Evolution in the social brain. Science 317, 1344-1347.

Eickhoff, S. B., and Bzdok, D. (2012). "Meta-analyses in basic and clinical neuroscience: state of the art and perspective," in $f M R I-$ Basics and Clinical Applications. 2nd edn, eds S. Ulmer and O. Jansen (Heidelberg: Springer).

Eickhoff, S. B., Bzdok, D., Laird, A. R., Kurth, F., and Fox, P. T. (2012). Activation likelihood estimation meta-analysis revisited. Neuroimage. 59, 2349-2361. doi: 10.1016/j.neuroimage.2011.09.017

Eickhoff, S. B., Bzdok, D., Laird, A. R., Roski, C., Caspers, S., Zilles, K., et al. (2011). Coactivation patterns distinguish cortical modules, their connectivity and functional differentiation. Neuroimage 57, 938-949. doi: 10.1016/j.neuroimage.2011.05.021

Eickhoff, S. B., Laird, A. R., Grefkes, C., Wang, L. E., Zilles, K., and Fox, P. T. (2009). Coordinate-based activation likelihood estimation meta-analysis of neuroimaging data: a random-effects approach based on empirical estimates of spatial uncertainty. Hum. Brain Mapp. 30, 2907-2926.

Ferry, A. T., Ongur, D., An, X., and Price, J. L. (2000). Prefrontal cortical projections to the striatum in macaque monkeys: evidence for an organization related to prefrontal 
networks. J. Comp. Neurol. 425, 447-470.

Feyerabend, P. (1975). Against Method: Outline of an Anarchist Theory of Knowledge. London: New Left Books.

Forbes, C. E., and Grafman, J. (2010). The role of the human prefrontal cortex in social cognition and moral judgment. Annu. Rev. Neurosci. 33, 299-324. doi: 10.1146/annurevneuro-060909-153230

Fox, D. F., and Raichle, M. E. (2007). Spontaneous fluctuations in brain activity observed with functional magnetic resonance imaging. Nat. Rev. Neurosci. 8, 700-711.

Fox, P. T., Laird, A. R., Fox, S. P., Fox, P. M., Uecker, A. M., Crank, M., et al. (2005). Brainmap taxonomy of experimental design: description and evaluation. Hum. Brain Mapp. $25,185-198$

Fox, P. T., and Lancaster, J. L. (2002). Opinion: mapping context and content: the brainmap model. Nat. Rev. Neurosci. 3, 319-321. doi: 10.1038/nrn789

Freeman, J. B., Schiller, D., Rule, N. O., and Ambady, N. (2010). The neural origins of superficial and individuated judgments about ingroup and outgroup members. Hum. Brain Mapp. 31, 150-159. doi: 10.1002/hbm.20852

Frey, S., Campbell, J. S., Pike, G. B., and Petrides, M. (2008). Dissociating the human language pathways with high angular resolution diffusion fiber tractography. J. Neurosci. 28, 11435-11444. doi: 10.1523/ JNEUROSCI.2388-08.2008

Fuster, J. M. (2001). The prefrontal cortex-an update: time is of the essence. Neuron 30, 319-333. doi: 10.1016/s0896-6273(01)00285-9

Gaffan, D. (2002). Against memory systems. Philos. Trans. R. Soc. Lond. B Biol. Sci. 357, 1111-1121. doi: 10.1098/rstb.2002.1110

Gallagher, H. L., and Frith, C. D. (2003). Functional imaging of 'theory of mind'. Trends Cogn. Sci. 7, 77-83. doi: 10.1016/S1364-6613(02)00025-6

Geva, S., Jones, P. S., Crinion, J. T., Price, C. J., Baron, J. C., and Warburton, E. A. (2011). The neural correlates of inner speech defined by voxel-based lesion-symptom mapping. Brain 134(Pt 10), 3071-3082. doi: 10.1093/brain/awr232

Gilbert, S. J., Spengler, S., Simons, J. S., Steele, J. D., Lawrie, S. M., Frith, C. D., et al. (2006). Functional specialization within rostral prefrontal cortex (area 10): a meta-analysis. J. Cogn. Neurosci. 18, 932-948.
Gläscher, J., Adolphs, R., Damasio, H., Bechara, A., Rudrauf, D., Calamia, M., et al. (2012). Lesion mapping of cognitive control and valuebased decision making in the prefrontal cortex. Proc. Natl. Acad. Sci. U.S.A. 109, 14681-14686. doi: 10.1073/pnas.1206608109

Goldman-Rakic，P. S. (1996). The prefrontal landscape: implications of functional architecture for understanding human mentation and the central executive. Philos. Trans. R. Soc. Lond. B Biol. Sci. 351, 1445-1453. doi: 10.1098/rstb.1996.0129

Gregory, C., Lough, S., Stone, V., Erzinclioglu, S., Martin, L., BaronCohen, S., et al. (2002). Theory of mind in patients with frontal variant frontotemporal dementia and Alzheimer's disease: theoretical and practical implications. Brain 125(Pt 4), 752-764. doi 10.1093/brain/awf079

Greicius, M. D., Supekar, K., Menon, V., and Dougherty, R. F. (2009). Resting-state functional connectivity reflects structural connectivity in the default mode network. Cereb. Cortex 19, 72-78. doi: 10.1093/cercor/bhn059

Gusnard, D. A., Akbudak, E., Shulman, G. L., and Raichle, M. E. (2001) Medial prefrontal cortex and self-referential mental activity: relation to a default mode of brain function. Proc. Natl. Acad. Sci. U.S.A. 98, 4259-4264. doi: 10.1073/pnas.071043098

Haber, S. N., Kunishio, K., Mizobuchi, M., and Lynd-Balta, E. (1995). The orbital and medial prefrontal circuit through the primate basal ganglia. J. Neurosci. 15(7 Pt 1), 4851-4867.

Harlow, J. M. (1848). Passage of an iron rod through the head. Boston Med. Surg. J. 39, 389-393.

Harlow, J. M. (1868). Recovery from the passage of an iron bar through the head. Publ. Mass. Med. Soc. 2, 327-347.

Hassabis, D., Kumaran, D., and Maguire, E. A. (2007). Using imagination to understand the neural basis of episodic memory. J. Neurosci. 27, 14365-14374. doi: 10.1523/JNEUROSCI.4549-07.2007

Hayden, B. Y., Nair, A. C., McCoy, A. N., and Platt, M. L. (2008). Posterior cingulate cortex mediates outcome-contingent allocation of behavior. Neuron 60, 19-25. doi 10.1016/j.neuron.2008.09.012

Holmes, C. J., Hoge, R., Collins, L., Woods, R., Toga, A. W., and Evans, A. C. (1998). Enhancement of MR images using registration for signal averaging. J. Comput. Assist. Tomogr. 22, 324-333.

Hornak, J., Rolls, E. T., and Wade, D. (1996). Face and voice expression identification in patients with emotional and behavioural changes following ventral frontal lobe damage. Neuropsychologia 34, 247-261. doi 10.1016/0028-3932(95)00106-9

Humphrey, N. K. (1978). "The social function of intellect," in Growing Points in Ethology, eds P. P. G. Bateson and R. A. Hinde (Cambridge: Cambridge University Press), 303-317.

Irle, E., Ruhleder, M., Lange, C. Seidler-Brandler, U., Salzer, S., Dechent, P., et al. (2010). Reduced amygdalar and hippocampal size in adults with generalized social phobia. J. Psychiatr. Neurosci. 35 126-131.

Jakobs, O., Langner, R., Caspers, S. Roski, C., Cieslik, E. C., Zilles, K. et al. (2012). Across-study and within-subject functional connectivity of a right temporo-parietal junction subregion involved in stimulus-context integration. Neuroimage 60, 2389-2398. doi 10.1016/j.neuroimage.2012.02.037

Jolly, A. (1966). Lemur social behaviour and primate intelligence. Science 153:501-506. doi 10.1126/science. 153.3735 .501

Kampe, K. K., Frith, C. D., Dolan, R. J., and Frith, U. (2001). Reward value of attractiveness and gaze. Nature 413, 589. doi: 10.1038/35098149

Kanai, R., Bahrami, B., Roylance, R., and Rees, G. (2012). Online social network size is reflected in human brain structure. Proc. Biol. Sci. 279, 1327-1334. doi 10.1098/rspb.2011.1959

Kellermann, T. S., Caspers, S., Fox, P. T., Zilles, K., Roski, C., Laird, A. R., et al. (2013). Task- and resting-state functional connectivity of brain regions related to affection and susceptible to concurrent cognitive demand. Neuroimage. 72, 69-82. doi: 10.1016/j.neuroimage.2013.01.046

Koechlin, E., and Hyafil, A. (2007). Anterior prefrontal function and the limits of human decisionmaking. Science 318, 594-598. doi: 10.1126/science. 1142995

Koenigs, M., Holliday, J., Solomon, J., and Grafman, J. (2010). Left dorsomedial frontal brain damage is associated with insomnia J. Neurosci. 30, 16041-16043. doi 10.1523/JNEUROSCI.3745-10.2010

Koenigs, M., Young, L., Adolphs, R., Tranel, D., Cushman, F., Hauser, M., et al. (2007). Damage to the prefrontal cortex increases utilitarian moral judgements. Nature 446 908-911. doi: 10.1038/nature05631

Laird, A. R., Eickhoff, S. B., Fox, P. M., Uecker, A. M., Ray, K. L., Saenz, Jr. J. J., et al. (2011). The brainmap strategy for standardization, sharing, and meta-analysis of neuroimaging data. BMC. Res. Notes 4: 349. doi: 10.1186/1756-0500-4-349

Laird, A. R., Eickhoff, S. B., Kurth, F., Fox, P. M., Uecker, A. M., Turner J. A., et al. (2009a). ALE metaanalysis workflows via the brainmap database: progress towards a probabilistic functional brain atlas. Front. Neuroinformatics 3:23. doi: 10.3389/neuro.11.023.2009

Laird, A. R., Eickhoff, S. B., Li, K. Robin, D. A., Glahn, D. C., and Fox, P. T. (2009b). Investigating the functional heterogeneity of the default mode network using coordinatebased meta-analytic modeling. $J$. Neurosci. 29, 14496-14505. doi: 10.1523/JNEUROSCI.4004-09.2009

Lane, R. D., Fink, G. R., Chau, P. M., and Dolan, R. J. (1997). Neural activation during selective attention to subjective emotional responses. Neuroreport. 8, 3969-3972.

Lebreton, M., Barnes, A., Miettunen, J., Peltonen, L., Ridler, K., Veijola, J., et al. (2009). The brain structural disposition to social interaction. Eur. J. Neurosci. 29, 2247-2252. doi: 10.1111/j.1460-9568.2009.06782.x

Leslie, A. M. (1987). Pretense and representation - the origins of theory of mind. Psychol. Rev. 94, 412-426. doi: 10.1037/0033-295X.94.4.412

Lewis, P. A., Rezaie, R., Brown, R., Roberts, N., and Dunbar, R. I. (2011). Ventromedial prefrontal volume predicts understanding of others and social network size. Neuroimage 57, 1624-1629. doi: 10.1016/j.neuroimage.2011.05.030

Lieberman, M. D. (2007). Social cognitive neuroscience: a review of core processes. Annu. Rev. Psychol. 58, 259-289.

Lombardo, M. V., Chakrabarti, B., Bullmore, E. T., Wheelwright, S. J., Sadek, S. A., Suckling, J., et al. (2009). Shared neural circuits for mentalizing about the self and others. J. Cogn. Neurosci. 22, 1623-1635. doi: 10.1162/jocn.2009.21287

Lotze, M., Veit, R., Anders, S., and Birbaumer, N. (2007). Evidence for a different role of the ventral and dorsal medial prefrontal cortex for social reactive aggression: an interactive fMRI study. Neuroimage 34, 470-478. doi: 10.1016/j.neuroimage.2006.09.028 
Maguire, E. A., Frackowiak, R. S., and Frith, C. D. (1997). Recalling routes around london: activation of the right hippocampus in taxi drivers. $J$. Neurosci. 17, 7103-7110.

Maguire, E. A., Gadian, D. G., Johnsrude, I. S., Good, C. D., Ashburner, J., Frackowiak, R. S., et al. (2000). Navigation-related structural change in the hippocampi of taxi drivers. Proc. Natl. Acad. Sci. U.S.A. 97, 4398-4403. doi: 10.1073/pnas.070039597

Mar, R. A. (2011). The neural bases of social cognition and story comprehension. Annu. Rev. Psychol. 62, 103-134. doi: 10.1146/annurevpsych-120709-145406

Margulies, D. S., Vincent, J. L., Kelly, C., Lohmann, G., Uddin, L. Q., Biswal, B. B., et al. (2009). Precuneus shares intrinsic functional architecture in humans and monkeys. Proc. Natl. Acad. Sci. U.S.A. 106, 20069-20074. doi: 10.1073/pnas.0905314106

McCoy, A. N., and Platt, M. L. (2005). Risk-sensitive neurons in macaque posterior cingulate cortex. Nat. Neurosci. 8, 1220-1227.

Mesulam, M. M. (1998). From sensation to cognition. Brain 121(Pt 6), 1013-1052.

Mitchell, J. P. (2009). Social psychology as a natural kind. Trends. Cogn. Sci. 13, 246-251.

Mitchell, J. P., Macrae, C. N., and Banaji, M. R. (2006). Dissociable medial prefrontal contributions to judgments of similar and dissimilar others. Neuron 50, 655-663. doi: 10.1016/j.neuron.2006.03.040

Mochizuki, H., and Saito, H. (1990). Mesial frontal lobe syndromes: correlations between neurological deficits and radiological localizations. Tohoku. J. Exp. Med. 161(Suppl), 231-239.

Monte, O. D., Krueger, F., Solomon, J., Schintu, S., Knutson, K. M., Strenziok, M., et al. (2012). A voxelbased lesion study on facial emotion recognition after penetrating brain injury. Soc. Cogn. Affect. Neurosci. doi: 10.1093/scan/nss041. (in press).

Moran, J. M., Jolly, E., and Mitchell, J. P. (2012). Social-cognitive deficits in normal aging. $J$. Neurosci. 32, 5553-5561. doi: 10.1523/JNEUROSCI.5511-11.2012

Nauta, W. J. (1971). The problem of the frontal lobe: a reinterpretation. J. Psychiatr. Res. 8, 167-187. doi: 10.1016/0022-3956

Nichols, T., Brett, M., Andersson, J., Wager, T., and Poline, J. B. (2005). Valid conjunction inference with the minimum statistic. Neuroimage 25, 653-660. doi: 10.1016/j.neuroimage.2004.12.005
Nicolle, A., Klein-Flugge, M. C., Hunt, L. T., Vlaev, I., Dolan, R. J., and Behrens, T. E. (2012). An agent independent axis for executed and modeled choice in medial prefrontal cortex. Neuron 75, 1114-1121. doi: 10.1016/j.neuron.2012.07.023

O'Keefe, J., and Dostrovsky, J. (1971). The hippocampus as a spatial map. Preliminary evidence from unit activity in the freely-moving rat. Brain Res. 34, 171-175. doi: 10.1016/0006-8993(71)90358-1

O'Reilly, R. C. (2010). The What and How of prefrontal cortical organization. Trends Neurosci. 33, 7.

Ochsner, K. N. (2008). The socialemotional processing stream: five core constructs and their translational potential for schizophrenia and beyond. Biol. Psychiatr. 64, 48-61. doi: 10.1016/j.biopsych.2008.04.024

Ochsner, K. N., Knierim, K., Ludlow, D. H., Hanelin, J., Ramachandran, T., Glover, G., et al. (2004a). Reflecting upon feelings: an fMRI study of neural systems supporting the attribution of emotion to self and other. J. Cogn. Neurosci. 16, 1746-1772. doi: 10.1162/0898929042947829

Ochsner, K. N., Ray, R. D., Cooper, J. C., Robertson, E. R., Chopra, S., Gabrieli, J. D., et al. (2004b). For better or for worse: neural systems supporting the cognitive downand up-regulation of negative emotion. Neuroimage 23, 483-499. doi: 10.1016/j.neuroimage.2004.06.030

Olsson, A., and Ochsner, K. N. (2008). The role of social cognition in emotion. Trends Cogn. Sci. 12, 65-71.

Pearson, J. M., Hayden, B. Y., Raghavachari, S., and Platt, M. L. (2009). Neurons in posterior cingulate cortex signal exploratory decisions in a dynamic multioption choice task. Curr. Biol. 19, 1532-1537. doi: 10.1016/j.cub.2009.07.048

Petrides, M., and Pandya, D. N. (2009). Distinct parietal and temporal pathways to the homologues of Broca's area in the monkey. PLoS Biol. 7:e1000170. doi: 10.1371/journal.pbio. 1000170

Phan, K. L., Taylor, S. F., Welsh, R. C., Ho, S. H., Britton, J. C., and Liberzon, I. (2004). Neural correlates of individual ratings of emotional salience: a trial-related fMRI study. Neuroimage 21, 768-780. doi: 10.1016/ j.neuroimage.2003.09.072

Phan, K. L., Wager, T., Taylor, S. F., and Liberzon, I. (2002). Functional neuroanatomy of emotion: a meta-analysis of emotion activation studies in PET and fMRI.
Neuroimage 16, 331-348. doi: 10.1006/nimg.2002.1087

Poldrack, R. A. (2006). Can cognitive processes be inferred from neuroimaging data? Trends Cogn. Sci. 10, 59-63.

Powell, J. L., Lewis, P. A., Dunbar, R. I., Garcia-Finana, M., and Roberts, N. (2010). Orbital prefrontal cortex volume correlates with social cognitive competence. Neuropsychologia 48, 3554-3562. doi: 10.1016/ j.neuropsychologia.2010.08.004

Premack, D., and Woodruff, G. (1978). Does the chimpanzee have a theory of mind. Behav. Brain Sci. 1, 515-526.

Rabin, J. S., Gilboa, A., Stuss, D. T., Mar, R. A., and Rosenbaum, R. S (2010). Common and unique neural correlates of autobiographical memory and theory of mind. $J$. Cogn. Neurosci. 22, 1095-1111. doi 10.1162/jocn.2009.21344

Rademacher, L., Krach, S., Kohls, G., Irmak, A., Grunder, G., and Spreckelmeyer, K. N. (2010). Dissociation of neural networks for anticipation and consumption of monetary and social rewards. Neuroimage 49, 3276-3285. doi: 10.1016/j.neuroimage.2009.10.089

Ramnani, N., and Owen, A. M. (2004). Anterior prefrontal cortex: insights into function from anatomy and neuroimaging. Nat. Rev. Neurosci. 5, 184-194. doi: 10.1038/nrn1343

Reetz, K., Dogan, I., Rolfs, A., Binkofski, F., Schulz, J. B., Laird, A. R., et al. (2012). Investigating function and connectivity of morphometric findings - exemplified on cerebellar atrophy in spinocerebellar ataxia 17 (SCA17). Neuroimage 62, 1354-1366. doi: 10.1016/j.neuroimage.2012.05.058

Rottschy, C., Caspers, S., Roski, C., Reetz, K., Dogan, I., Schulz, J. B., et al. (2012). Differentiated parietal connectivity of frontal regions for "what" and "where" memory. Brain Struct. Funct. doi: 10.1007/s00429012-0476-4. (in press).

Saleem, K. S., Kondo, H., and Price, J. L. (2008). Complementary circuits connecting the orbital and medial prefrontal networks with the temporal, insular, and opercular cortex in the macaque monkey. $J$. Comp. Neurol. 506, 659-693. doi: 10.1002/cne.21577

Sallet, J., Mars, R. B., Noonan, M. P., Andersson, J. L., O’Reilly, J. X., Jbabdi, S., et al. (2011). Social network size affects neural circuits in macaques. Science 334, 697-700. doi: 10.1126/science. 1210027

Satterthwaite, T. D., Elliott, M. A., Gerraty, R. T., Ruparel, K.,
Loughead, J., Calkins, M. E., et al. (2013). An improved framework for confound regression and filtering for control of motion artifact in the preprocessing of restingstate functional connectivity data. Neuroimage 64, 240-256. doi: 10.1016/j.neuroimage.2012.08.052

Saver, J. L., and Damasio, A. R. (1991). Preserved access and processing of social knowledge in a patient with acquired sociopathy due to ventromedial frontal damage. Neuropsychologia 29, 1241-1249. doi: 10.1016/0028-3932(91)90037-9 Schacter, D. L., Addis, D. R., and Buckner, R. L. (2007) Remembering the past to imagine the future: the prospective brain. Nat. Rev. Neurosci. 8, 657-661. doi: 10.1038/nrn2213

Schilbach, L., Bzdok, D., Timmermans, B., Fox, P. T., Laird, A. R., Vogeley, K., et al. (2012). Introspective minds: using ALE meta-analyses to study commonalities in the neural correlates of emotional processing, social \& unconstrained cognition. PLOS ONE 7:e30920. doi: 10.1371/journal. pone. 0030920

Schilbach, L., Wilms, M., Eickhoff, S. B., Romanzetti, S., Tepest, R., Bente, G., et al. (2010). Minds made for sharing: initiating joint attention recruits rewardrelated neurocircuitry. J. Cogn. Neurosci. 22, 2702-2715. doi: 10.1162/jocn.2009.21401

Schultz, W., Dayan, P., and Montague, P. R. (1997). A neural substrate of prediction and reward. Science 275, 1593-1599. doi: $10.1126 /$ science. 275.5306 .1593

Scoville, W. B., and Milner, B. (1957). Loss of recent memory after bilateral hippocampal lesions. J. Neurol. Neurosurg. Psychiatr. 20, 11-21. doi: 10.1136/jnnp.20.1.11

Shamay-Tsoory, S. G., and AharonPeretz, J. (2007). Dissociable prefrontal networks for cognitive and affective theory of mind: a lesion study. Neuropsychologia 45, 3054-3067. doi: 10.1016/ j.neuropsychologia.2007.05.021

Shamay-Tsoory, S. G., Aharon-Peretz, J., and Perry, D. (2009). Two systems for empathy: a double dissociation between emotional and cognitive empathy in inferior frontal gyrus versus ventromedial prefrontal lesions. Brain 132, 617-627. doi: 10.1093/brain/awn279

Shamay-Tsoory, S. G., Tibi-Elhanany, Y., and Aharon-Peretz, J. (2006). The ventromedial prefrontal cortex is involved in understanding affective but not cognitive 
theory of mind stories. Soc. Neurosci. 1(3-4), 149-166. doi: $10.1080 / 17470910600985589$

Shamay-Tsoory, S. G., Tomer, R., Berger, B. D., Goldsher, D., and Aharon-Peretz, J. (2005). Impaired "affective theory of mind" is associated with right ventromedial prefrontal damage. Cogn. Behav. Neurol. 18, 55-67.

Spreng, R. N., Mar, R. A., and Kim, A. S. (2009). The common neural basis of autobiographical memory, prospection, navigation, theory of mind, and the default mode: a quantitative meta-analysis. $J$. Cogn. Neurosci. 21, 489-510. doi: 10.1162/jocn.2008.21029

Stone, V. E., Baron-Cohen, S., Calder, A., Keane, J., and Young, A. (2003). Acquired theory of mind impairments in individuals with bilateral amygdala lesions. Neuropsychologia 41, 209-220.

Stone, V. E., Baron-Cohen, S., and Knight, R. T. (1998). Frontal lobe contributions to theory of mind. J. Cogn. Neurosci. 10, 640-656.

Stuss, D. T., Gallup, Jr. G. G., and Alexander, M. P. (2001). The frontal lobes are necessary for 'theory of mind'. Brain 124(Pt 2), 279-286. doi: 10.1093/brain/124.2.279

Suddendorf, T., and Corballis, M. C. (2007). The evolution of foresight: what is mental time travel, and is it unique to humans? Behav. Brain Sci. 30, 299-313. discussion: 313-351. doi: 10.1017/S0140525X07001975

Tomasello, M., Call, J., and Hare, B. (2003). Chimpanzees understand psychological states - the question is which ones and to what extent. Trends Cogn. Sci. 7, 153-156.

Turkeltaub, P. E., Eden, G. F., Jones, K. M., and Zeffiro, T. A. (2002).
Meta-analysis of the functional neuroanatomy of single-word reading: method and validation. Neuroimage 16, 765-780. doi: 10.1006/nimg.2002.1131

Turkeltaub, P. E., Eickhoff, S. B., Laird, A. R., Fox, M., Wiener, M., and Fox, P. (2012). Minimizing within-experiment and withingroup effects in Activation Likelihood Estimation metaanalyses. Hum. Brain Mapp. 33, 1-13. doi: 10.1002/hbm.21186

Turner, J. A., and Laird, A. R. (2012). The cognitive paradigm ontology: design and application. Neuroinformatics 10, 57-66. doi: 10.1007/s12021-011-9126-x

Van Overwalle, F. (2009). Social cognition and the brain: a meta-analysis. Hum. Brain Mapp. 30, 829-858. doi: 10.1002/hbm.20547

Vann, S. D., Aggleton, J. P., and Maguire, E. A. (2009). What does the retrosplenial cortex do? Nat. Rev. Neurosci. 10, 792-803. doi: 10.1038/nrn2733

Vincent, J. L., Snyder, A. Z., Fox, M. D., Shannon, B. J., Andrews, J. R., Raichle, M. E., et al. (2006). Coherent spontaneous activity identifies a hippocampalparietal memory network. J. Neurophysiol. 96, 3517-3531. doi: 10.1152/jn.00048.2006

von Bechterew, W. (1900). Demonstration eines Gehirns mit Zerstörung der vorderen und inneren Teile der Hirnrinde beider Schläfenlappen. Neurol. Zentbl. 19, 990-991.

Wagner, D. D., Kelley, W. M., and Heatherton, T. F. (2011). Individual differences in the spontaneous recruitment of brain regions supporting mental state understanding when viewing natural social scenes. Cereb. Cortex 21, 2788-2796. doi: 10.1093/cercor/bhr074

Walter, H., Abler, B., Ciaramidaro A., and Erk, S. (2005). Motivating forces of human actions. Neuroimaging reward and social interaction. Brain Res. Bull. 67, 368-381. doi: 10.1016/j.brainresbull.2005.06.016

Wilson, C. R., Gaffan, D., Browning, P. G., and Baxter, M. G. (2010). Functional localization within the prefrontal cortex: missing the forest for the trees? Trends Neurosci. 33, 533-540. doi: 10.1016/j.tins.2010.08.001

Wood, J. N., and Grafman, J. (2003). Human prefrontal cortex: processing and representational perspectives. Nat. Rev. Neurosci. 4, 139-147. doi: 10.1038/nrn1033

Yarkoni, T., Poldrack, R. A., Nichols, T. E., Van Essen, D. C., and Wager, T. D. (2011). Large-scale automated synthesis of human functional neuroimaging data. Nat. Meth. 8 , 665-670. doi: 10.1038/nmeth.1635

Yeterian, E. H., Pandya, D. N., Tomaiuolo, F., and Petrides, M. (2012). The cortical connectivity of the prefrontal cortex in the monkey brain. Cortex 48, 58-81. doi: 10.1016/j.cortex.2011. 03.004

Young, L., Bechara, A., Tranel, D. Damasio, H., Hauser, M., and Damasio, A. (2010). Damage to ventromedial prefrontal cortex impairs judgment of harmful intent. Neuron 65, 845-851. doi: 10.1016/j.neuron.2010.03.003

Zaki, J., Weber, J., Bolger, N., and Ochsner, K. (2009). The neural bases of empathic accuracy. Proc. Natl. Acad. Sci.
U.S.A. 106, 11382-11387. doi: 10.1073/pnas.0902666106

Zink, C. F., Tong, Y., Chen, Q., Bassett, D. S., Stein, J. L., and Meyer-Lindenberg, A. (2008). Know your place: neural processing of social hierarchy in humans. Neuron 58, 273-283. doi: 10.1016/j.neuron.2008.01.025

zu Eulenburg, P., Caspers, S., Roski, C., and Eickhoff, S. B. (2012). Meta-analytical definition and functional connectivity of the human vestibular cortex. Neuroimage 60, 162-169. doi: 10.1016/j.neuroimage.2011.12.032

Conflict of Interest Statement: The authors declare that the research was conducted in the absence of any commercial or financial relationships that could be construed as a potential conflict of interest.

Received: 03 March 2013; paper pending published: 03 April 2013; accepted: 14 May 2013; published online: 29 May 2013.

Citation: Bzdok D, Langner R, Schilbach L, Engemann DA, Laird AR, Fox PT and Eickhoff SB (2013) Segregation of the human medial prefrontal cortex in social cognition. Front. Hum. Neurosci. 7:232. doi: 10.3389/fnhum.2013.00232

Copyright (c) 2013 Bzdok, Langner, Schilbach, Engemann, Laird, Fox and Eickhoff. This is an open-access article distributed under the terms of the Creative Commons Attribution License, which permits use, distribution and reproduction in other forums, provided the original authors and source are credited and subject to any copyright notices concerning any third-party graphics etc. 